\title{
Integrin $\alpha 5 \beta 1$ and p53 convergent pathways in the control of anti-apoptotic proteins PEA-15 and survivin in high-grade glioma
}

\author{
G Renner ${ }^{1,5}$, H Janouskova ${ }^{1,5}$, F Noulet ${ }^{1}$, V Koenig ${ }^{1}$, E Guerin ${ }^{2}$, S Bär ${ }^{3,6}$, J Nuesch ${ }^{3}$, F Rechenmacher ${ }^{4}$, S Neubauer ${ }^{4}$, H Kessler ${ }^{4}$, \\ A-F Blandin ${ }^{1}$, L Choulier ${ }^{1}$, N Etienne-Selloum ${ }^{1}$, M Lehmann ${ }^{1}$, I Lelong-Rebel ${ }^{1}$, S Martin ${ }^{1}$ and M Dontenwill ${ }^{*} 1$
}

Integrin $\alpha 5 \beta 1$ expression is correlated with a worse prognosis in high-grade glioma. We previously unraveled a negative crosstalk between integrin $\alpha 5 \beta 1$ and p53 pathway, which was proposed to be part of the resistance of glioblastoma to chemotherapies. The restoration of p53 tumor-suppressor function is under intensive investigations for cancer therapy. However, p53-dependent apoptosis is not always achieved by p53-reactivating compounds such as Nutlin-3a, although full transcriptional activity of p53 could be obtained. Here we investigated whether integrin $\alpha 5 \beta 1$ functional inhibition or repression could sensitize glioma cells to Nutlin-3a-induced p53-dependent apoptosis. We discovered that $\alpha 5 \beta 1$ integrin-specific blocking antibodies or small RGD-like antagonists in association with Nutlin-3a triggered a caspase (Casp) 8/Casp 3-dependent strong apoptosis in glioma cells expressing a functional p53. We deciphered the molecular mechanisms involved and we showed the crucial role of two anti-apoptotic proteins, phosphoprotein enriched in astrocytes 15 (PEA-15) and survivin in glioma cell apoptotic outcome. PEA-15 is under $\alpha 5 \beta 1$ integrin/AKT (protein kinase B) control and survivin is a p53-repressed target. Moreover, interconnections between integrin and p53 pathways were revealed. Indeed PEA-15 repression by specific small-interfering RNA (siRNA)-activated p53 pathway to repress survivin and conversely survivin repression by specific siRNA decreased $\alpha 5 \beta 1$ integrin expression. This pro-apoptotic loop could be generalized to several glioma cell lines, whatever their p53 status, inasmuch PEA-15 and survivin protein levels were decreased. Our findings identify a novel mechanism whereby inhibition of $\alpha 5 \beta 1$ integrin and activation of p53 modulates two anti-apoptotic proteins crucially involved in the apoptotic answer of glioma cells. Importantly, our results suggest that high-grade glioma expressing high level of $\alpha 5 \beta 1$ integrin may benefit from associated therapies including integrin antagonists and repressors of survivin expression.

Cell Death and Differentiation (2016) 23, 640-653; doi:10.1038/cdd.2015.131; published online 16 October 2015

In recent years, integrins have attracted increasing interest for their potential to act as tumor therapeutic targets. ${ }^{1,2}$ First recognized as adhesion molecules to the extracellular matrix (ECM), it is now acknowledged that they act as receptors regulating intracellular signaling and cellular responses. ${ }^{3}$ Integrins are $\alpha \beta$ protein heterodimers whose association defines the specificity for ECM components. Regulating crosstalks between cells and their microenvironment, integrins are relevant in key aspects of tumors. Depending on the tumor type, the expression of specific integrins differs between tumoral tissues and their corresponding healthy tissues. For example, $a 5 \beta 1$ and $\alpha \mathrm{v} \beta 3 / \beta 5$ integrin overexpression on neovessels during tumor angiogenic switch led to the proposition of new anti-angiogenic therapies. ${ }^{4}$ In tumor cells, integrins impact on proliferation/survival, therapy resistances and tumor recurrence. $a 5 \beta 1$ integrin has emerged recently and has been shown to participate in aggressiveness of solid tumors ${ }^{5-9}$ as reviewed in Schaffner et al. ${ }^{10}$ High expression of a5 integrin is associated with a decrease in patient overall survival, making $a 5 \beta 1$ integrin an important factor in resistance to therapies. Numerous preclinical data support the ability of integrin antagonists to disrupt integrin signaling pathways leading to inhibition of angiogenesis and/or tumor growth but also to sensitization toward therapies.

Glioblastomas (GBM) or WHO grade 4 astrocytoma are the most refractory brain tumors to conventional/targeted therapies.

${ }^{1}$ Integrins and Cancer, Faculté de Pharmacie, UMR7213 CNRS, LBP, Tumoral Signaling and Therapeutic Targets Department, Université de Strasbourg, Faculté de Pharmacie, Illkirch, France; ${ }^{2} E A 3430$, Université de Strasbourg, Strasbourg, France; ${ }^{3}$ Tumor Virology Division (F010), Deutsches Krebsforschungszentrum/German Cancer Research Center (DKFZ), Heidelberg, Germany and ${ }^{4}$ Department Chemie, Institute for Advanced Study and Center of Integrated Protein Studies, Technische Universität München, Garching, Germany

${ }^{*}$ Corresponding author: M Dontenwill, Integrins and Cancer, Faculté de Pharmacie, UMR7213 CNRS, LBP, Tumoral Signaling and Therapeutic Targets, Université de Strasbourg, Faculté de Pharmacie, Illkirch, 67401 France. Tel: +33 3 68854267; Fax: +33 3 68854313; E-mail: monique.dontenwill @ unistra.fr

${ }^{5}$ Equal first co-authors.

${ }^{6}$ Present address: UMR7156 CNRS, Université de Strasbourg, France.

Abbreviations: Bax, BCL2-associated X protein; BCL2, B-cell lymphoma 2; Birc5, baculoviral IAP repeat containing 5; Casp, caspase; ECM, extracellular matrix; FADD, Fas-associated protein with death domain; GSK $\beta$, glycogen synthase kinase 3 beta; HDM2, human double minute 2; IAP, inhibitor of apoptosis proteins; JNK, c-Jun $\mathrm{N}$-terminal kinase; MAPK, mitogen-activated protein kinase; PARP, poly ADP ribose polymerase; PEA-15, phosphoprotein enriched in astrocytes 15; PI3K, phosphoinositide 3-kinase; PKB (or AKT), protein kinase B; siRNA, small-interfering RNA; TMZ, temozolomide

Received 06.3.2015; revised 15.7.2015; accepted 01.9.2015; Edited by JC Marine; published online 16.10.15 
The prognosis of GBM patients remains worse and has not improved since the approbation of the Stupp protocol. ${ }^{11}$ Even if new strategies had appeared promising, relapses mostly occurred because of innate and acquired therapy resistances. GBM recapitulate the fundamental hallmarks of cancer. ${ }^{12}$ All of these hallmarks can be modulated by the ECM and its sensing receptors such as integrins. ${ }^{13}$ Despite some negative outcome with av $\beta 3$ integrin antagonist in GBM treatment, ${ }^{14}$ integrins remain pertinent targets for anticancer agents in view of their implications in various aspects of cancer progression. To move forward with integrins as therapeutic targets, more fundamental views of the crucial effects they may modulate must be obtained.

The tumor-suppressor p53 is implicated in tumor growth suppression, as well as in induction of apoptosis. As the guardian of the genome, its transcriptional activity governs genes implicated in cell cycle arrest, apoptosis but also DNA repair, metabolism. ${ }^{15}$ About $50 \%$ of cancers express a mutant functionally affected p53 protein. ${ }^{16,17}$ In GBM, integrated genomic analysis identified subtypes differing in their p53 status. ${ }^{18}$ Even if p53 appears as one of the most frequently mutated gene in $\mathrm{GBM},{ }^{19}$ a window of wild-type p53 activation is possibly a therapeutic solution for a non-negligible number of GBM. Several ways for reactivation of p53 are currently under study in preclinical and clinical trials focusing mainly on the inhibition of the interactions between p53 and its negative regulator human double minute 2 (HDM2) ${ }^{20,21}$ The consequences of p53 activation in tumor cells are variable ranging from cell cycle arrest/senescence and/or apoptosis and the balance between these outcomes determines the tumor regression in a tumor type-dependent way. ${ }^{22,23}$ As apoptosis may be preferred over cell cycle arrest/senescence upon p53 reactivation, it is crucial to determine the factors implicated in p53-triggered apoptosis.

Along with others, we demonstrated that p53-induced activation either by genotoxic drugs ${ }^{24}$ or by inhibitors of HDM2 such as Nutlin-3a-triggered ${ }^{25}$ senescence rather than apoptosis in GBM. We characterized a negative crosstalk between a5 $\beta 1$ integrin and p53wt implicated in temozolomide (TMZ) resistance. ${ }^{8}$ Antagonists of $a 5 \beta 1$ integrin pushed TMZ-treated cells from senescence toward apoptosis while modulating the p53 pathway. ${ }^{24}$ Nutlin-3a, by inhibiting p53-HDM2 interaction, induced a huge increase in p53 activity but also decreased the expression level of a5 integrin in p53wt GBM or colon cancer cells. ${ }^{8,26}$ Here, we investigated the potential benefit of targeting GBM with antagonists of $a 5 \beta 1$ integrin and Nutlin-3a. We demonstrated the crucial role of two anti-apoptotic proteins, phosphoprotein enriched in astrocytes 15 (PEA-15) and survivin, in the apoptotic outcome of this dual targeting therapy.

\section{Results}

Inhibition of $\alpha 5 \beta 1$ integrin sensitizes p53wt glioma cells to Nutlin-3a. We demonstrated that $a 5 \beta 1$ integrin interferes with the p53 pathway and that Nutlin-3a $(10 \mu \mathrm{M})$ represses the a5 integrin subunit through the activation of $\mathrm{p53}$. $^{8,24} \mathrm{We}$ wondered whether $a 5$ integrin repression would sensitize glioma cells to Nutlin-3a. We treated U87MG cells overexpressing (U87MG-a5 high) or repressed (U87MG-a5 low) for a5 integrin with different doses of Nutlin-3a and evaluated their clonogenic potential. U87MG-a5 low cells were more sensitive to Nutlin-3a compared with their a5 high counterparts at all concentrations used (Figure 1a). In addition, functional inhibition of $a 5 \beta 1$ integrin with a specific non-peptidic antagonist, compound $2 / \mathrm{K} 4 \mathrm{c},{ }^{27}$ sensitized U87MG-a5 high cells to Nutlin-3a (Figure 1b). Interestingly, although each compound alone partially inhibited clonogenic cell survival, their combination appeared more efficient (Figure 1b). Trypan blue exclusion assays revealed that only drug association had a clear cytotoxic effect (Figure 1c). Accordingly, the amount of apoptotic cells was largely increased by the combination, reaching $56 \pm 6 \%$ of the total cell population as compared with $20 \pm 5$ in $\mathrm{K} 34 \mathrm{c}$ and $16 \pm 4 \%$ in Nutlin-3a-treated cells (Figure 1d). Western blot analysis showed cleaved poly ADP ribose polymerase (PARP) and cleaved caspase (Casp) 3 only in the combination-treated cells confirming a massive induction of apoptosis by this treatment (Figure 1e). As expected, Nutlin-3a increased the p53 protein stability and activity (phosphorylation at ser15; Figure 1e). This increase was not associated with apoptotic markers. Although K34c had no effect on p53 by itself, its association with Nutlin$3 a$ not only increased the p53 phosphorylation but also induced apoptosis (Figure 1e). Similar results were obtained in a primary GBM cell line (T20) with endogenous expression of a5 integrin and a p53wt protein (Figure 7a, Supplementary Figure S1a), although in this case Nutlin-3a had already an effect that was increased by K34c.

We then treated U87MG-a5 high cells with integrin function blocking antibodies (IIA1 for a5 integrin and 69.6.5 for $a \mathrm{~V}$ integrin). The specific anti-a5 integrin antibody was able, in combination with Nutlin-3a, to induce a strong increase in apoptotic markers (Figure 2a). RGD-like integrin small antagonists $^{27}$ (Supplementary Table 1) alone or in association with Nutlin-3a were next evaluated. Data clearly demonstrated that only antagonists with a high affinity for $a 5 \beta 1$ integrin (compound 1 and 2/K34c) were able to sensitize cells toward apoptosis in contrast to compound 3 (high affinity for $a \mathrm{v}$ integrins) (Figure 2b). The increase in apoptotic markers was related to an increase in Casp 3 activity as only specific antibodies or small molecules against a5 integrin had a significant impact in association with Nutlin-3a (Figure 2c). This increased Casp 3 activity obtained with $a 5 \beta 1$ integrin antagonists was lost in U87MG-a5 low cells (Figure 2d), which already increased their basal level of active Casp 3 with a further increase by Nutlin-3a (Figure 2e).

Thus, our data suggested that disabling the a5 $\beta 1$-triggered survival pathways in association with the pharmacological reactivation of $\mathrm{p53}$ by Nutlin-3a is synthetic lethal in glioma cells.

Integrin $\alpha 5 \beta 1$ antagonist inhibits the AKT/PEA-15/Casp 8 pathway to trigger apoptosis. We next investigated which integrin signaling pathways may be inhibited by a5 $\beta 1$ integrin antagonists to allow apoptosis during p53 reactivation. We checked the implication of the phosphoinositide 3-kinase (PI3K)/AKT (protein kinase B) survival pathway known to be under integrin control. ${ }^{28}$ The amount of active AKT (pser473AKT) was higher in U87MG-a5 high cells compared with 

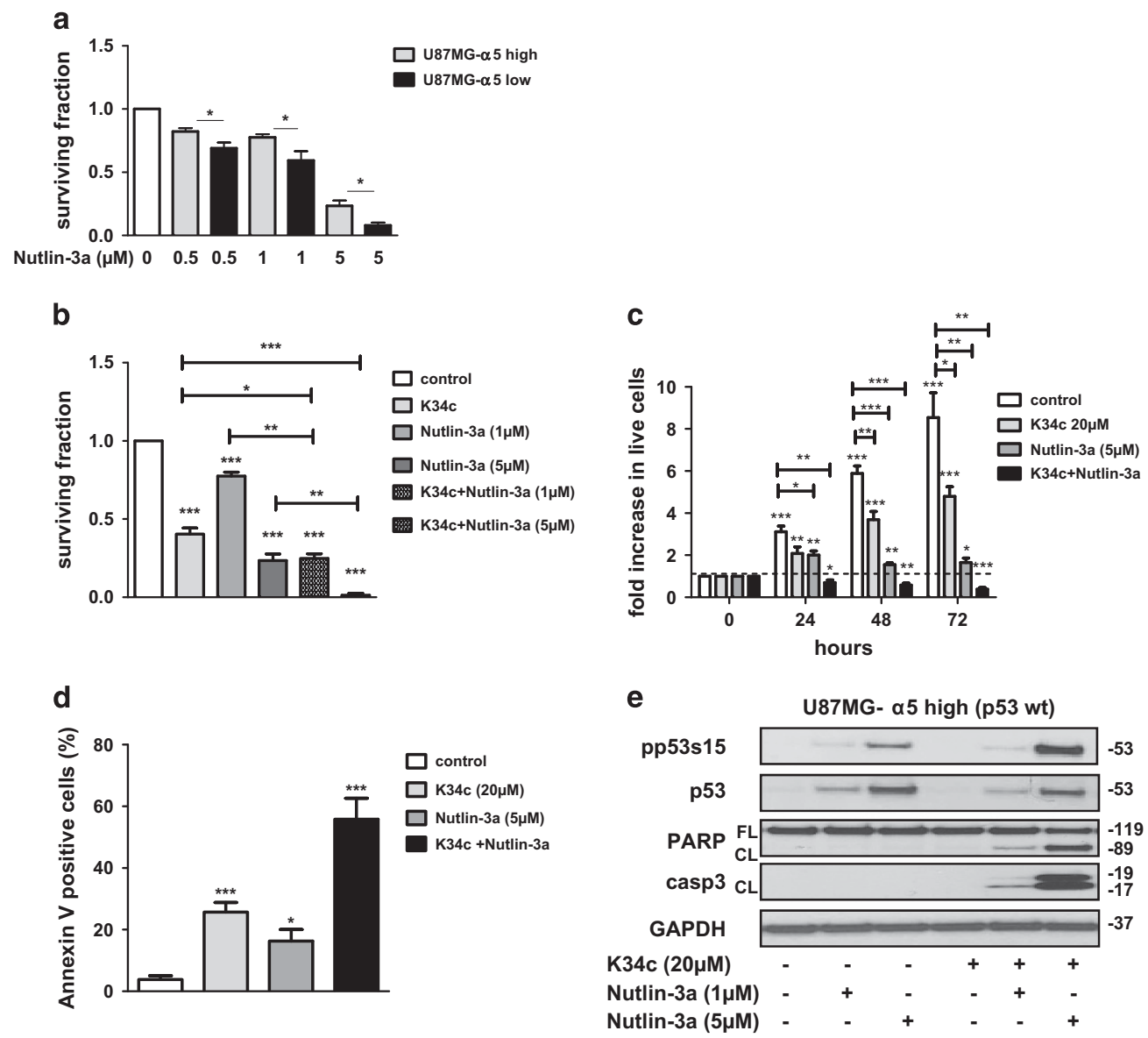

Figure 1 Inhibition of $\alpha 5 \beta 1$ integrin sensitizes U87MG- $\alpha 5$ high glioma cells to Nutlin-3a-induced apoptosis. (a) Dose response of Nutlin-3a on clonogenic survival of U87MG$\alpha 5$ high cells as compared with U87MG- $\alpha 5$ low cells. Cells were treated during 3 days with different doses of Nutlin-3a and recovery allowed for 10 days. Histograms represent the mean \pm S.E.M. $(n=4)$ of surviving fractions of Nutlin-3a-treated cells versus control solvent-treated cells. The plating efficiencies of U87MG- $\alpha 5$ high cells and U87MG- $\alpha 5$ low cells were equivalent $(0.36 \pm 0.03$ and $0.34 \pm 0.06$, respectively) and the empty bar represents the reference for both cell lines. (b) Clonogenic survival of U87MG- $\alpha 5$ high cells after $\mathrm{K} 34 \mathrm{c}(20 \mu \mathrm{M})$, Nutlin-3a $(1$ or $5 \mu \mathrm{M})$ or combination treatments. Histograms represent the mean \pm S.E.M. $(n=4)$ of surviving fraction of drug-treated cells versus control solvent-treated cells. (c) Proliferation of U87MG- $\alpha 5$ high cells with similar treatments as in b. Data are reported as fold increase in live cells at 24-, 48- and 72-h treatment as compared with plated live cells at time 0 . Histograms represent the mean \pm S.E.M. of four independent experiments. (d) Apoptosis in U87MG- $\alpha 5$ high cells was measured after 24-h treatment by the Annexin V/PI FACS analysis. Early and late apoptosis are combined in the histograms. Mean \pm S.E.M. of four independent experiments. (e) p53 stabilization/activation and apoptotic markers were detected by western blot analysis of total p53, p53 phosphorylated at ser15 (pp53s15), PARP full length (FL), PARP cleaved $(\mathrm{CL})$ and cleaved caspase 3 (casp3 CL). A representative western blot of U87MG- $\alpha 5$ high cells treated during $12 \mathrm{~h}$ with solvent, K34c $(20 \mu \mathrm{M})$, Nutlin-3a (1 or $5 \mu \mathrm{M})$ or both together is shown. GAPDH was used as the loading control. For all panels: mean \pm S.E.M. of $n$ experiments with ${ }^{*} P<0.05,{ }^{* *} P<0.01,{ }^{* \star *} P<0.001$

U87MG-a5 low cells. This activity is decreased by the $a 5 \beta 1$ integrin antagonist K34c (Figure 3a) and further decreased by Nutlin-3a (Figure 3b). Direct inhibition of AKT by MK-2206, completely suppressed pser473-AKT, induced Casp 3 cleavage and Casp 3 activity, effects that were further increased by the addition of Nutlin-3a (Supplementary Figure S2). In tumoral cells including glioma, AKT controls the stability and the antiapoptotic function of the protein PED/PEA-15 by its phosphorylation on ser116. ${ }^{29,30}$ We explored the effect of K34c on PED/ PEA-15 expression and phosphorylation in U87MG-a5 high cells. Both were decreased by K34c but not affected by Nutlin3a (Figure 3c). The role of PEA-15 in the cell apoptosis was further investigated by the use of specific small-interfering RNA (siRNA). After depletion of PEA-15 and Nutlin-3a treatment, Casp 3 cleavage and activity looked like the one obtained by the association of K34c and Nutlin-3a (Figure 3d). Similar results were obtained in the primary GBM cell line, T20
(Supplementary Figure S1b). Inversely, overexpression of PEA-15 by transfection with a pcDNA-PEA-15 vector completely inhibited the induction of apoptosis triggered by the co-treatment (Figure 3e).

Integrin-mediated death and/or anoikis have been linked to the activation of Casp 8 (Marcon et al. ${ }^{31}$ ) and PEA-15 is known to bind to Casp 8 and to block apoptosis through its inhibition. ${ }^{32}$ We evaluated Casp 8 activation by western blot in U87MG-a5 high cells treated by K34c, Nutlin-3a or both. Enhanced cleaved Casp 8 was detected only in cells treated with both drugs (Figure 3f). Interestingly, the Casp 3 activity was completely blocked by cell preincubation with the specific Casp 8 inhibitor (Z-IETD-fmk) before treatments (Figure 3g). In addition, inhibition of cell proliferation by the co-treatment (K34c and Nutlin-3a) was equally reversed by preincubation of the cells with an inhibitor of Casp 3 (z-DEVD-fmk) or the inhibitor of Casp 8 (Figure 3h). 
a

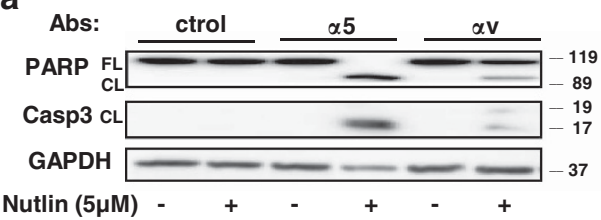

b

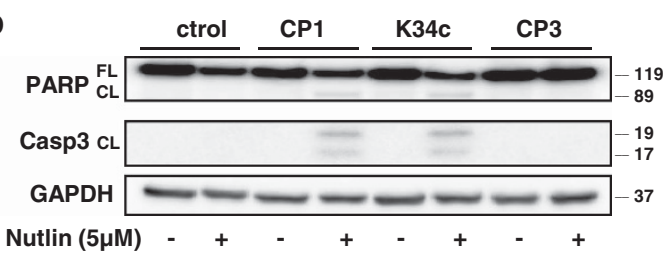

C
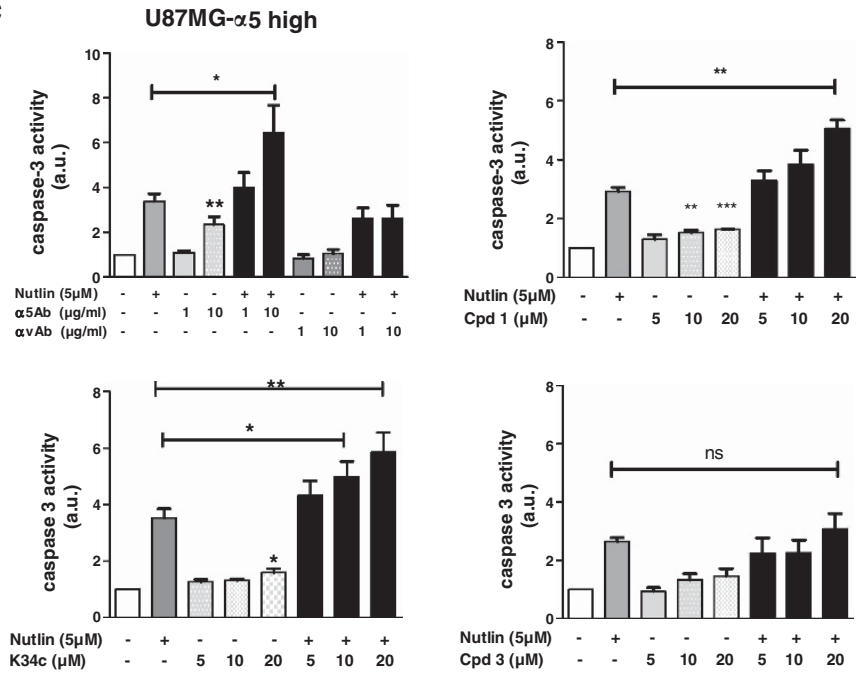

d

U87MG- $\alpha 5$ low
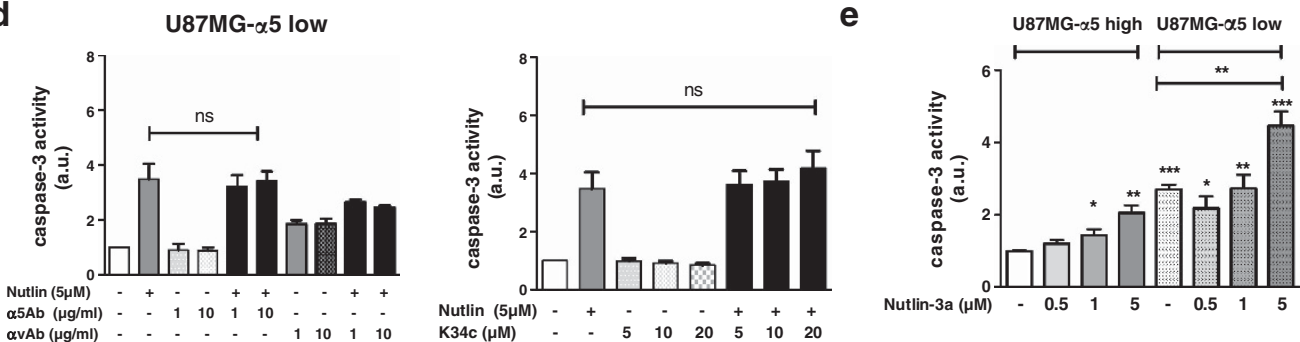

Figure 2 The $\alpha 5$ integrin is specifically involved in the resistance to p53-dependent apoptosis. (a) Effects of integrin-blocking antibodies with/without Nutlin-3a on apoptotic markers. Antibodies (10 $\mu \mathrm{g} / \mathrm{ml}$ ) specific for $\alpha 5$ integrin (IIA1) or for $\alpha \mathrm{V}$ integrin (69.6.5) were incubated during $12 \mathrm{~h}$ with U87MG- $\alpha 5$ high cells in the absence or presence of Nutlin$3 a(5 \mu \mathrm{M})$. A representative western blot (out of three independent experiments) of cleaved apoptotic markers PARP and Casp 3 is shown. (b) Effects of RGD-like integrin antagonists with/without Nutlin-3a on apoptotic markers. Compound 1 and 2/K34c are selective for $\alpha 5 \beta 1$ integrin ( 2.3 and $3.1 \mathrm{nM}$ affinities, respectively) and compound 3 is selective for $\alpha \mathrm{v} \beta 3$ integrin (108 nM for $\alpha 5 \beta 1$ integrin and $0.65 \mathrm{nM}$ for $\alpha \mathrm{v} \beta 3$ integrin) as reported in Ray et al. ${ }^{27}$ and in Supplementary Table 1. Antagonists were incubated in similar conditions as in a. A representative western blot (out of three independent experiments) of cleaved apoptotic markers PARP and Casp 3 is shown. (c) Fluorimetric Casp 3 activity dosages in U87MG- $\alpha 5$ high cells treated with integrin-blocking antibodies specific for $\alpha 5$ (IIA1) or $\alpha \mathrm{V}$ (69.6.5) integrin (1 and 10 $\mu \mathrm{g} / \mathrm{ml})$ or with the RGD-like integrin antagonists $(5,10,20 \mu \mathrm{M})$ in absence or presence of Nutlin-3a. Histograms represent the fold increase in fluorescence emitted by the cleavage of z-DEVD-AMC (10 $\mu \mathrm{M})$ in the different conditions as compared with control non-treated cells. Mean \pm S.E.M. of three to four independent experiments. (d) Similar experiments as in c in U87MG- $\alpha 5$ low cells. (e) Comparison of Nutlin-3a dose-dependent effects on Casp 3 activity in U87MG- $\alpha 5$ high and U87MG- $\alpha 5$ low cells. Mean \pm S.E.M. of three to four independent experiments. For all panels: mean \pm S.E.M. with ${ }^{*} P<0.05,{ }^{* \star} P<0.01,{ }^{* \star *} P<0.001$; NS, nonsignificant

Taken together, our data suggest that sensitization to Nutlin-3a pro-apoptotic effect by a5 $\beta 1$ integrin antagonists is linked to the inhibition of an integrin/AKT/PEA-15/Casp 8 signaling pathway in U87MG-a5 high cells.

Implication of p53 activation in the induction of apoptosis. We next examined the p53-dependent factors underlying the pro-apoptotic outcome. Transcription of p53 transcriptionally induced genes, fas (Figure 4a), bax, noxa, p21 and hdm2 (Supplementary figure S3a), was increased by Nutlin-3a confirming the activation of $p 53$. The a5 $\beta 1$ antagonist $\mathrm{K} 34 \mathrm{c}$ alone was unable to change the level of p53 targets and a significant increase over Nutlin-3a effects was only obtained for bax and noxa (Supplementary Figure S3a) pro-apoptotic targets but not fas (Figure 4a), p21 and $h d m 2$ (Supplementary Figure S3a) when it was associated with Nutlin-3a. However, FAS (Figure 4b) and B-cell lymphoma 2 (BCL2)-associated $X$ protein (BAX) (Supplementary Figure S3b) proteins were not increased by the co-treatment. Similarly, p21 and HDM2 proteins were increased by Nutlin-3a but not further increased by K34c (Supplementary Figure S3b). It is already known that p53 also has the capability to repress oncogenic/anti-apoptotic factors, ${ }^{33}$ which is crucial to elicit p53-dependent robust apoptosis. ${ }^{34}$ Three repressible p53-target genes, birc5 (baculoviral inhibitor of apoptosis protein (IAP) repeat containing 5; Figure 4c), c-myc and bcl-2 
(Supplementary Figure S3c) were largely decreased at the mRNA level after Nutlin-3a treatment but only birc5 was further decreased by the addition of K34c (Figure 4c and Supplementary Figure S3c). At the protein level, survivin encoded by birc5 gene (Figure 4d) and bcl-2 (Supplementary Figure S3d) appeared significantly downregulated by the combo treatment as compared with Nutlin-3a alone. As a confirmation of a role of p53-dependent survivin decrease in the induction of apoptosis, depletion of survivin by specific siRNA in U87MG-a5 high cells led to a slight increase in cleaved Parp/Casp 3 and Casp 3 activity but addition of K34c significantly further increased these effects to the level of K34c/Nutlin-3a co-treatment (Figure 4e). Similar results were obtained in the primary GBM cell line, T20 (Supplementary Figure S1c). Inversely, overexpression of survivin in U87MG-a5 high cells led to a complete inhibition of Parp/Casp 3 cleavage and Casp 3 activation, further confirming its anti-apoptotic role (Figure $4 \mathrm{f}$ ).

Data indicated that p53 was highly activated by Nutlin-3a in U87MG cells as several known target genes were transcriptionally increased or decreased as were their corresponding proteins. This p53 activation alone did not allow a full pro-apoptotic program. When a5 $\beta 1$ integrin pathway was concomitantly blocked by $\mathrm{K} 34 \mathrm{c}$, pro-apoptotic targets were increased at the mRNA level but not at the protein level. However, the anti-apoptotic birc5 gene and the corresponding protein survivin were both further decreased by the combination treatment. Taken together, data thus suggested that repression of two anti-apoptotic proteins is crucial for induction of apoptosis in glioma cells expressing high level of $a 5$ integrin. PEA-15 is mainly under the control of the $a 5 \beta 1$ integrin and repressed by a specific integrin antagonist and survivin is mainly repressed by Nutlin-dependent p53 activation.

$\alpha 5 \beta 1$ integrin and p53 pathways crosstalk through PEA-15 and survivin. We reasoned that PEA-15 may be one of the links between $a 5 \beta 1$ integrin and p53 pathways. Interestingly, similarly to the depletion of $a 5$ integrin, ${ }^{8}$ depletion of PEA-15 in U87MG-a5 high cells stabilized and activated p53 (Figure 5a). Addition of Nutlin-3a to siPEA-15 cells significantly enhanced the p53 expression/ phosphorylation compared with control si-nt cells (Figure 5a).
PEA-15-depleted cells exhibited an enhanced basal level of fas and a decreased level of birc5, bcl-2 and c-myc mRNA again in a similar manner than depletion of a5 integrin (Figure 5b). Interestingly, p53 stabilization/activation by PEA-15 depletion were of the same order of magnitude than those obtained with $\mathrm{TMZ}$ alone but association of both treatment did not enhance the genotoxic activation of p53 (Figure 5a) suggesting that the mode of activation of p53 has an impact on the cell answer. As PEA-15 depletion led to an accumulation of p53 protein, modulation of HDM2 is possibly implicated. In fact, si-PEA-15 decreased significantly HDM2 protein level (Figure $5 \mathrm{c}$ ) and PEA-15 overexpression increased it (Figure $5 \mathrm{~d}$ ). As the transcription of hdm2 was not affected by PEA-15 (Figure 5b), we studied the regulation of HDM2 on a posttranscriptional level. The half-life of HDM2 was clearly enhanced by PEA-15 overexpression in U87MGa5 high cells (Figure $5 d$ ).

Data thus confirmed that PEA-15 linked integrin and p53 pathways, presumably by regulating the p53-HDM2 interaction. These results also show that the decrease of $a 5$ integrin or PEA-15 expression levels mostly affected known p53repressed target genes supporting their role in p53-dependent robust apoptosis. In LNZ308 cells (p53KO), repression of PEA-15 did not affect birc5 or bcl-2 mRNA levels confirming the p53 pathway implication (Supplementary Figure S4).

We showed elsewhere that, by activating p53, Nutlin-3a inhibited the expression of a5 integrin, which in turn makes cells more susceptible to death. ${ }^{8,26}$ Previous works suggested that survivin positively regulates the a5 integrin expression. ${ }^{35,36}$ We therefore investigated if survivin depletion may affect $a 5$ integrin expression in glioma cells. In U87MG-a5 high cells, Nutlin-3a treatment or survivin depletion led to a decrease in a5 integrin expression level (Figure 6a), which was further significantly and dose dependently enhanced by K34c (Figure 6b). Survivin repression affected both a5 integrin mRNA and protein level, although survivin overexpression only increased the protein level (Figure 6c). Thus, transcriptional and posttranscriptional regulation of $a 5$ integrin expression may be driven by survivin. In fact, the half-life of a5 integrin was increased by overexpression of survivin in U87MG-a5 high cells (Figure 6d). In addition, the decrease in a5 integrin expression by survivin repression and inhibition of the integrin was a

Figure 3 Integrin $\alpha 5 \beta 1$ antagonist inhibits the AKT/PEA-15/Casp 8/Casp 3 pathway to trigger apoptosis. (a) Expression of $\alpha 5$ integrin modulates the activity of AKT. Comparison of p-AKTser473 and AKT expression levels by western blot in U87MG- $\alpha 5$ high and U87MG- $\alpha 5$ low cells without/with K34c (20 $\mu$ M) after 12-h treatment. Histograms represent the mean \pm S.E.M. $(n=3)$ of p-AKTser473 protein normalized to the loading control GAPDH as compared with non-treated control U87MG- $\alpha 5$ high cells. (b) Inhibition of AKT activity by K34c $(20 \mu \mathrm{M})$, Nutlin-3a $(1$ and $5 \mu \mathrm{M})$ or both together in U87MG- $\alpha 5$ high cells. Cells were analyzed by immunoblots for active AKT (p-AKTser473) and p-GSK $\beta$ ser9 (as a substrate of AKT) in the different conditions. Graphs represent the mean \pm S.E.M. $(n=3)$ of protein expression levels normalized to the loading control GAPDH and compared with the solvent-treated control cells. (c) PEA-15 protein is under the control of $\alpha 5$ integrin. Cells treated as in $\mathbf{b}$ were analyzed by immunoblots for PEA-15 and p-PEA15ser116. Graphs represent the mean \pm S.E.M. $(n=3)$ of protein expression levels normalized to the loading control GAPDH and compared with the solvent-treated control cells. (d and e) PEA-15 is involved in the control of apoptosis. (d) U87MG- $\alpha 5$ high cells were transduced with non-targeting siRNA control (si-nt) or specific for PEA-15 (si-PEA-15) during $24 \mathrm{~h}$ and treated with K34c $(20 \mu \mathrm{M})$, Nutlin-3a $(5 \mu \mathrm{M})$ or both for $12 \mathrm{~h}$. Apoptotic markers (cleaved PARP and Casp 3) and PEA-15 expression levels were analyzed by immunoblots. Histograms represent the Casp 3 activity (cleavage of z-DEVD-AMC) in similar conditions and compared with solvent-treated si-nt U87MG- $\alpha 5$ high cells. Mean \pm S.E.M. of three independent experiments. (e) U87MG- $\alpha 5$ high cells were transiently transfected with pcDNA empty vector or pcDNA-PEA-15 vector. After $24 \mathrm{~h}$, cells were treated with $\mathrm{K} 34 \mathrm{c}(20 \mu \mathrm{M})$, Nutlin-3a $(5 \mu \mathrm{M})$ or both during $12 \mathrm{~h}$ and cell lysates analyzed by immunoblots for apoptotic markers and for PEA-15 expression levels. Histograms represent the Casp 3 activity (cleavage of z-DEVD-AMC) in similar conditions and compared with solvent-treated U87MG- $\alpha 5$ high cells. Mean \pm S.E.M. of three independent experiments. (f-h) Casp 8 is implicated in apoptosis. (f) Immunoblot analysis of Casp 8 (CL, cleaved; FL, full length) in U87MG- $\alpha 5$ high cells treated during $12 \mathrm{~h}$ with K34c $(20 \mu \mathrm{M})$, Nutlin-3a $(5 \mu \mathrm{M})$ or both. (g) Casp 3 activity (cleavage of z-DEVD-AMC) without or with cell pre-treatment (1 h) with z-IETD-fmk (50 $\mu \mathrm{M})$, a specific inhibitor of Casp 8. (h) Proliferation of U87MG- $\alpha 5$ high cells treated with K34c and Nutlin-3a without or with pre-treatment with a Casp 3 inhibitor (z-DEVD-fmk - $50 \mu \mathrm{M}$ ) or a Casp 8 inhibitor (z-IETD-fmk $-50 \mu \mathrm{M})$. Data are reported as fold increase in live cells at 24-, 48- and 72-h treatment as compared with plated live cells at time 0 . Histograms represent the mean \pm S.E.M. of three independent experiments. For all panels: mean \pm S.E.M. with ${ }^{*} P<0.05,{ }^{* \star} P<0.01,{ }^{* \star}{ }^{*} P<0.001$; NS, nonsignificant 
general phenomenon in glioma cells (Figure 6e).

Results uncovered two convergent and interconnected pathways, controlling glioma cell apoptosis and implicating $a 5 \beta 1 /$ PEA-15 loop, which modulates the 053 pathway and the p53/survivin loop modulating a5 $\beta 1$ integrin pathway.

Repression of PEA-15 and survivin is synthetic lethal in glioma cells. We next looked for a potential relationship between $a 5 \beta 1$ integrin, PEA-15, survivin expression levels and p53 status in different glioma cell lines, two patientderived primary GBM cell lines (T17 and T20) and two GBM stem-like cells ( $\mathrm{NCH} 644$ and $\mathrm{NCH} 421 \mathrm{k}$ ). No significant relationships could be recorded between a5 expression and PEA-15 or survivin expression in basal culture conditions (Figure 7a, left). Interestingly, a5 integrin expression was higher in p53wt cells but inversely survivin was statistically more expressed in cells with a mutant p53 (Figure 7a, right). Data are in line with those we obtained recently in a cohort of patient biopsies indicating that $a 5$ integrin mRNA level is high in p53wt tumors ${ }^{8}$ suggesting that it participates to the functional inhibition of p53 pathway in glioma. An enhanced level of survivin in p53 mutant cells fits pertinently with its

a
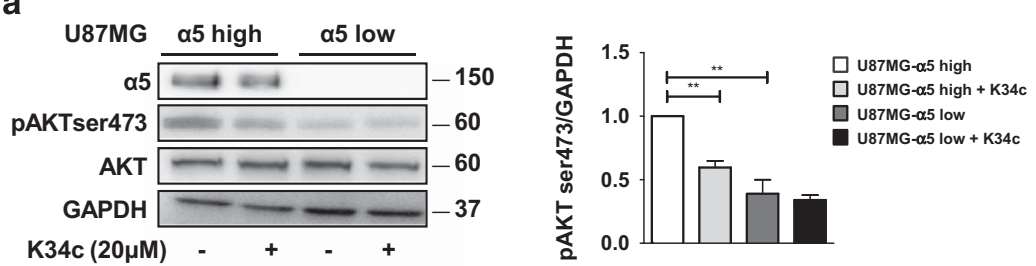

b
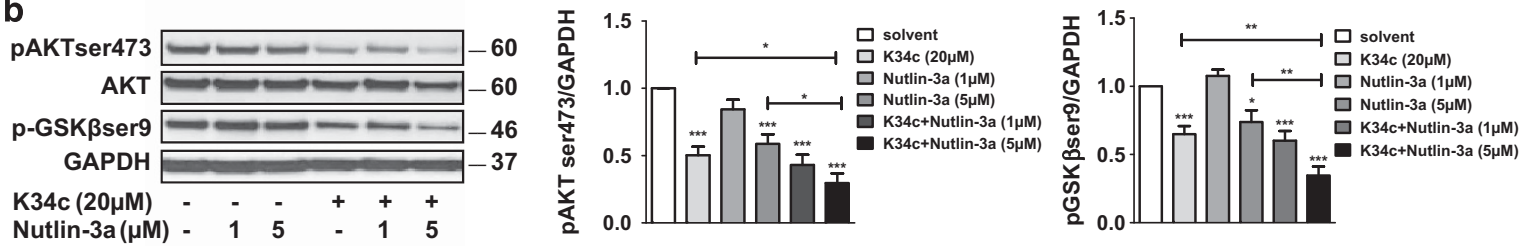

\section{C}
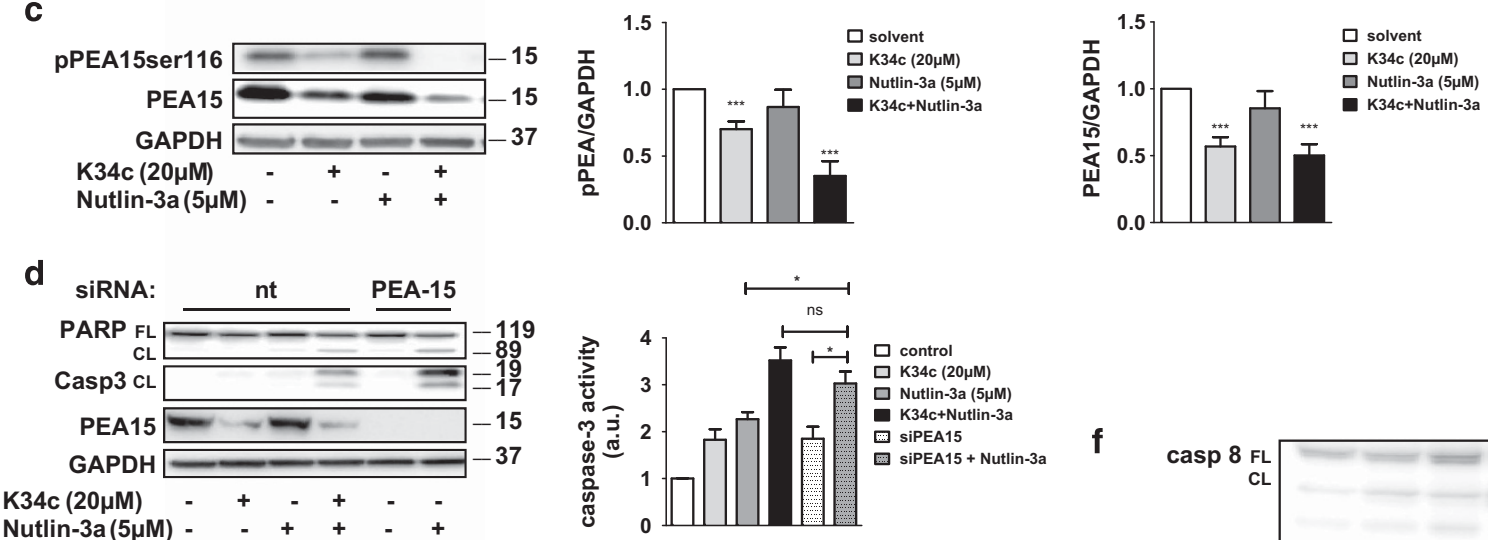

e pcDNA: ctrl $\longrightarrow$ PEA-15
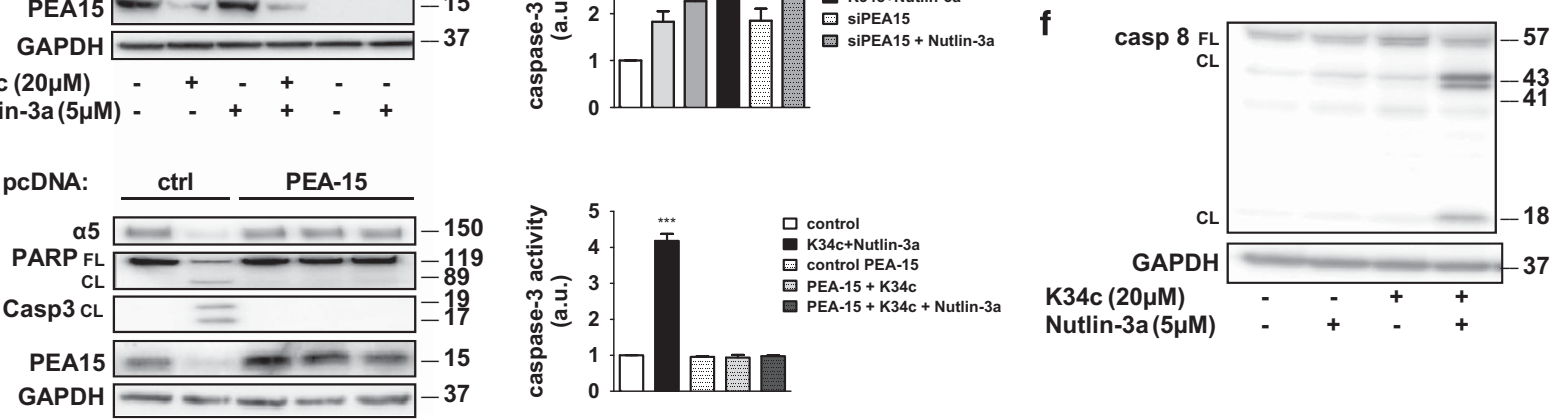

K34c $(20 \mu \mathrm{M})$ Nutlin-3a $(5 \mu \mathrm{M})-\quad+-\quad+$
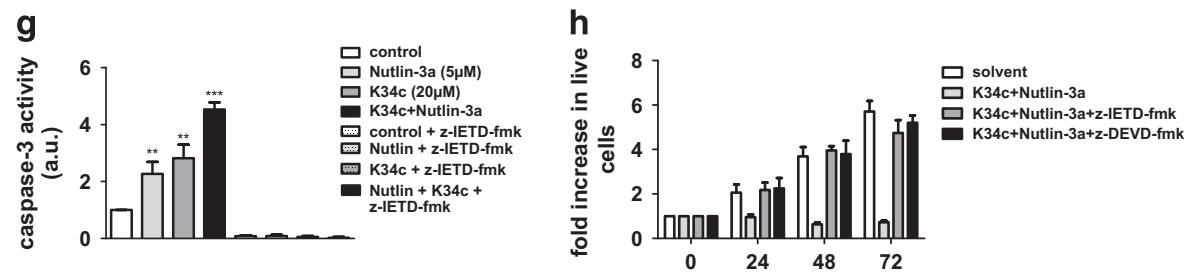
negative control by a functional p53. PEA-15 did not correlate with any p53 status. To further explore the relationship between PEA-15 and a5 integrin, we compared U87MG and U373MG control cells with their respective counterparts overexpressing the a5 subunit. It appeared (Figure $7 \mathrm{~b}$ ) that expression of phosphoPEA-15 and PEA-15 is related to the expression of a5 integrin in both cell lines. Thus, data suggested that under conditions where a5 integrin is highly expressed (in recurrent tumors, for example, DeLay et al. ${ }^{37}$ ), PEA-15 may be considered as an anti-apoptotic factor.

Based on these results, we questioned the pertinence of PEA-15 and survivin as targets for pro-apoptotic signaling in other glioma cell lines. We evaluated the effects of Nutlin-3a with/without K34c in U373MG-a5 high cells (mutant p53). In these cells, Nutlin-3a, K34c or both did not inhibit proliferation (Figure 7c) and did not induce apoptosis (Figure 7d and Supplementary Figure S5b). K34c decreased the expression of PEA-15 but Nutlin-3a did not decrease survivin as expected. However, PARP and Casp 3 were cleaved with survivin siRNA in association with K34c (Figure 7e).

In similar experimental conditions, Nutlin-3a, K34c or both had no effect on LNZ308 (p53KO) proliferation and apoptosis (Figures $7 f$ and $g$ and Supplementary Figure S5c). Neither survivin (due to the absence of p53) nor PEA-15 (due to a low expression of a5 integrin - Supplementary Figure S5a) expression levels were modulated by Nutlin-3a or K34c, respectively (Figure $7 \mathrm{~g}$ ). In these cells, repression of both survivin and PEA-15 by specific siRNAs recapitulated cell apoptosis (Figure $7 \mathrm{~h}$ ).

These results add evidences that only repression of both anti-apoptotic proteins together triggers apoptosis in glioma cells. In p53 mutant/KO cells, Nutlin-3a is unable to repress survivin, which may be overpassed by survivin-specific siRNA. K34c did not affect PEA-15 expression in a5 low-expressing cells, which may be overpassed by PEA-15specific siRNA. Data thus confirm the implication of PEA-15 and survivin as major factors in glioma resistance to apoptosis and suggest a synthetic lethal interaction between them.

\section{Discussion}

GBM are highly resistant to apoptosis even if they express a functional p53 protein. To achieve successful anticancer therapy, it is primordial to characterize pathways hindering the apoptotic answer in the context of p53 activation. We demonstrated a negative crosstalk between $a 5 \beta 1$ integrin and p53 pathways in glioma, which was confirmed in this study. According to our new data, two main conclusions are proposed: (1) the inhibition of $a 5 \beta 1$ integrin oncogenic pathways sensitizes glioma cells to p53-reactivationdependent apoptotic cues, and (2) interconnected antiapoptotic pathways depending on two proteins, PEA-15 and survivin, may explain glioma resistance to apoptosis. These two proteins may be interesting therapeutic targets for proapoptotic strategies in high-grade glioma.

PEA-15 is a multifunctional protein known (1) to modulate $a 5 \beta 1$ integrin activity, ${ }^{38}$ (2) to be included in the $a 5 \beta 1$ adhesome $^{39}$ and (3) to bind to Fas-associated protein with death domain (FADD) and/or Casp 8 in the apoptotic death-inducing signaling complex. ${ }^{32}$ PEA-15 can be phosphorylated on ser116 by AKT and on ser104 by protein kinase $C$ leading to different functional implications. ${ }^{40}$ In fact, unphosphorylated PEA-15 acts as a tumor suppressor by sequestering extracellular signal-regulated kinase in the cytoplasm and thus inhibits proliferation. In tumoral cells with an exacerbated AKT signaling, phosphorylated-PEA-15 switches from tumor suppressor to tumor promoter by interfering with FADD/Casp 8 and apoptosis. A tumorsuppressor role of PEA-15 was proposed in brain tumors based on its decreased expression at the mRNA and protein level in GBM compared with low-grade astrocytoma with $50 \%$ of GBM nevertheless having high PEA-15 expression. ${ }^{41,42}$ Interestingly, expression of pser116-PEA-15 was confined in specific intratumoral area with the strongest immunoreactivity in perinecrotic area. ${ }^{43}$ Our preliminary results indicated that a5 integrin could also be localized in these particular area in GBM specimens (data not shown). Although suspected to be inversely regulated during tumor progression, PEA-15 has been involved in therapy resistances in tumors including glioma. ${ }^{30,32,44-46}$ However, no relationship between PEA-15 and the p53 pathway has been described to date. Our data demonstrated that PEA-15 has an impact on p53 stability/activity and is essential to inhibit p53-induced apoptosis. Interestingly, PEA-15 overexpression increased HDM2 protein stability, an effect presumably involved in the inhibition of p53. We cannot exclude that PEA-15 acts through other mechanisms. We showed that PEA-15 mainly impacted on the p53-dependent repression of anti-apoptotic/ survival genes, which was shown to be dependent of mitogen-activated protein kinase (MAPK)/c-Jun N-terminal kinase (JNK). ${ }^{33}$ Indeed, PEA-15 is able to inhibit JNK and p38 MAPK $^{47}$ and its repression may activate the JNK/p53 pathway. Elucidation of the fine tuning of p53 activity by PEA-15 deserves, however, further studies.

Survivin, which belongs to the IAP family, is relevant in $\mathrm{GBM}^{48}$ and has been correlated with malignant astrocytic tumors. ${ }^{49,50}$ Survivin participates to glioma radio- and chemotherapy resistance ${ }^{50-52}$ and a selective inhibitor of survivin, YM155, is currently under clinical trials. ${ }^{53-55}$ Beside the p53-dependent transcriptional control of survivin, other pathways including the PI3K/AKT or the integrin-linked kinase pathway driven by tyrosine kinase receptors or integrins ${ }^{51,50,56}$ have been implicated in its regulation. Survivin is thus confirmed as a pertinent therapeutic target in GBM and strategies aiming to decrease its expression should be considered. In line with its capability to modulate the a5 integrin expression, repression of survivin will be particularly relevant in high-grade glioma overexpressing a5 integrin.

The restoration of p53 tumor-suppressor function is increasingly considered as an attractive therapeutic strategy for hematological and solid tumors. Several small inhibitors of HDM2-p53 complex are proposed and some already entered clinical trials. Nutlin-3a was the lead compound in the field ${ }^{57}$ but few data addressed its effects in GBM. Here, we show that it activated p53-dependent transcription of pro-apoptotic targets but also repressed anti-apoptotic genes confirming other works ${ }^{25}$ without inducing full apoptosis in glioma cells overexpressing the $a 5 \beta 1$ integrin. Repression of anti-apoptotic/survival genes in addition with induction of pro-apoptotic 
a

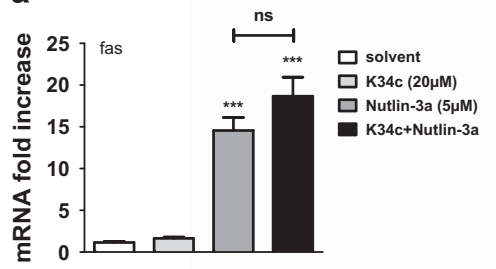

c

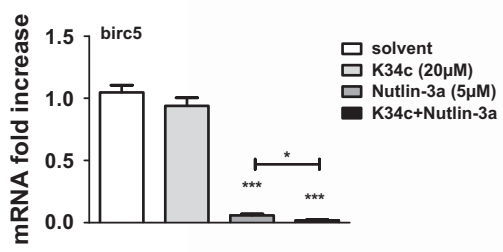

e

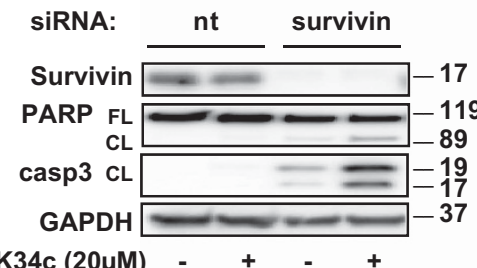

f

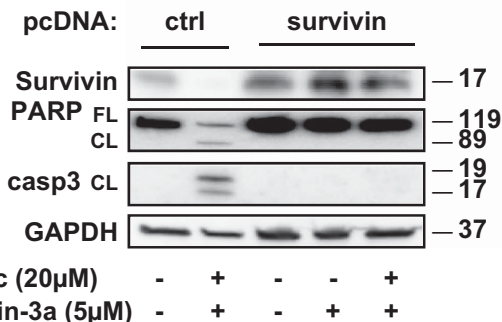

b
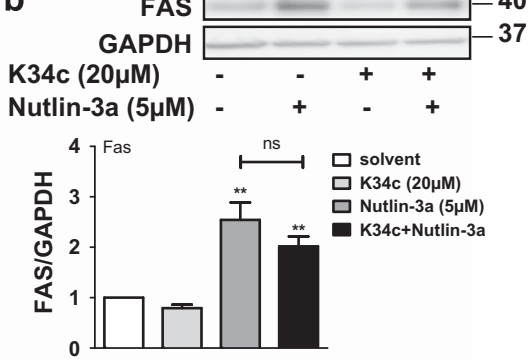

d

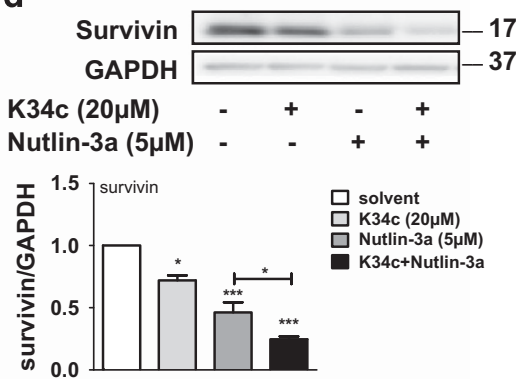

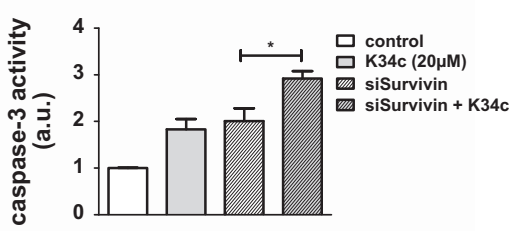

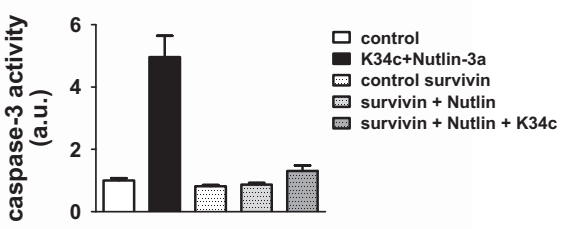

Figure 4 Implication of the p53 pathway in cell apoptotic outcome. (a-d) U87MG- $\alpha 5$ high cells were treated during $12 \mathrm{~h}$ with $\mathrm{K} 34 \mathrm{c}(20 \mu \mathrm{M})$, Nutlin-3a $(5 \mu \mathrm{M})$ or both. Cells in (a) and (c) were analyzed for mRNA (normalized to GAPDH) of fas and birc5, respectively. (b and d) representative western blots of FAS and survivin, respectively, are shown and histograms represent the mean \pm S.E.M. of three separate experiments with GAPDH as the reference loading control. (e and f) Survivin is implicated in the control of apoptosis. (e) U87MG- $\alpha 5$ high cells were transduced with non-targeting siRNA control (si-nt) or specific for survivin (si-survivin) during $24 \mathrm{~h}$ and treated with $\mathrm{K} 34 \mathrm{c}(20 \mu \mathrm{M})$ for $12 \mathrm{~h}$. (f) U87MG- $\alpha 5$ high cells were transfected with the pcDNA control vector (ctrl) or with the pcDNA-survivin vector (survivin) during $24 \mathrm{~h}$ and treated with the indicated drugs for $12 \mathrm{~h}$. Apoptotic markers (cleaved PARP and Casp 3) and survivin expression levels were analyzed by immunoblots. Histograms represent the Casp 3 activity (cleavage of z-DEVDAMC) in similar conditions and compared with si-nt solvent-treated U87MG- $\alpha 5$ high cells. Mean \pm S.E.M. of three independent experiments. Mean \pm S.E.M. with ${ }^{*} P<0.05$, ${ }^{\star \star} P<0.01,{ }^{\star \star *} P<0.001$; NS, nonsignificant

targets was shown to critically control the apoptotic outcome of RITA-treated cancer cells. ${ }^{34,58-60}$ In glioma cells, we found that Nutlin-3a behaved as shown previously for RITA regarding the p53 transcriptional repression activity. ${ }^{34}$ However, high expression of $a 5 \beta 1$ integrin conferred another anti-apoptotic signaling, which we identified to be in part supported by PEA-15. We propose that this integrin may be integrated in the growing list of molecular determinants of the p53 tumorsuppressor activity. ${ }^{61-63}$

Response to chemotherapy may be hindered by p53mediated cell cycle arrest or senescence. ${ }^{64,65}$ As shown here, functional inhibition of the $a 5 \beta 1$ integrin may represent a new way to sensitize glioma cells to the p53-dependent proapoptotic effect of Nutlin-3a. Importantly, data shown here stress the important contribution of two anti-apoptotic proteins, PEA-15 and survivin, in the control of apoptosis. Inhibition of integrin/PEA-15 loop sustains the p53 activation loop, which in turn activates a negative feedback loop through survivin (Figure 8). Robust apoptosis is uniquely obtained by the combined repression of both proteins, whatever the cell p53 status. Our results may have clinical implications in the context of p53-reactivating drugs/radio-chemotherapies and integrindependent antitumoral strategies. We identified new interacting signaling pathways, which may be exploited in glioma but 
also in other solid tumors depending on the oncogenic activity of the $a 5 \beta 1$ integrin. According to our results, a potential survival advantage for sub-population of patients with glioma expressing high level of the $a 5 \beta 1$ integrin may be obtained through the association of $a 5 \beta 1$ integrin antagonists with drugs able to repress survivin. a

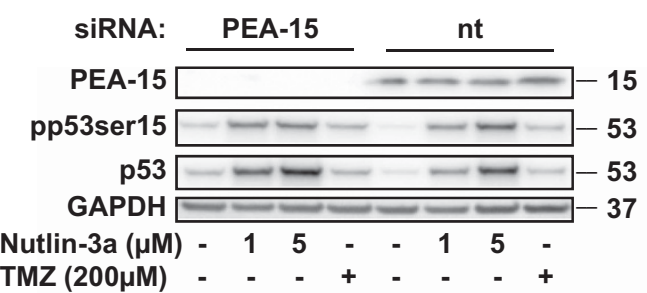

$\begin{array}{lllllllll}\text { Nutlin-3a }(\mu M) & - & 1 & 5 & - & - & 1 & 5 & - \\ \text { TMZ }(200 \mu M) & - & - & - & + & - & - & - & +\end{array}$

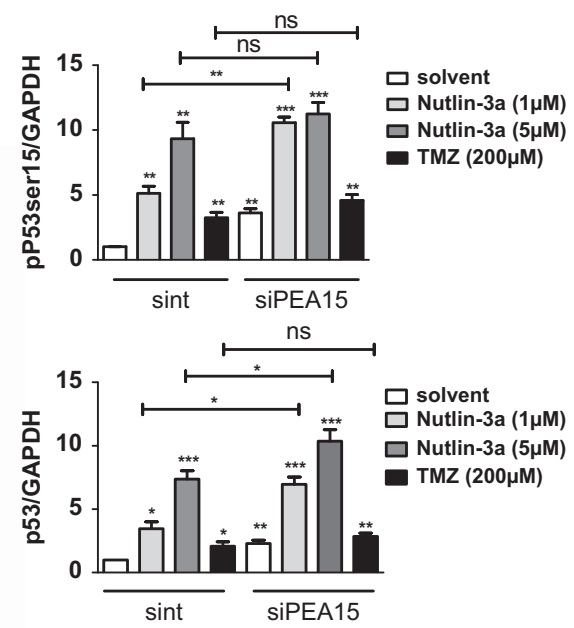

b

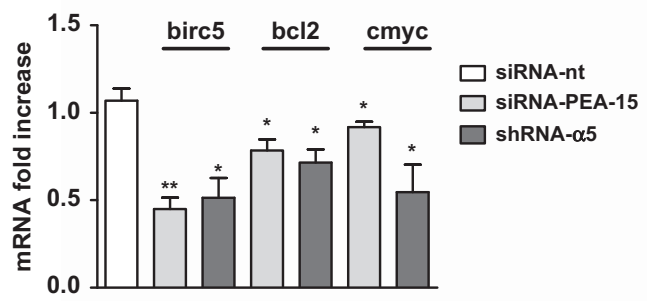

C
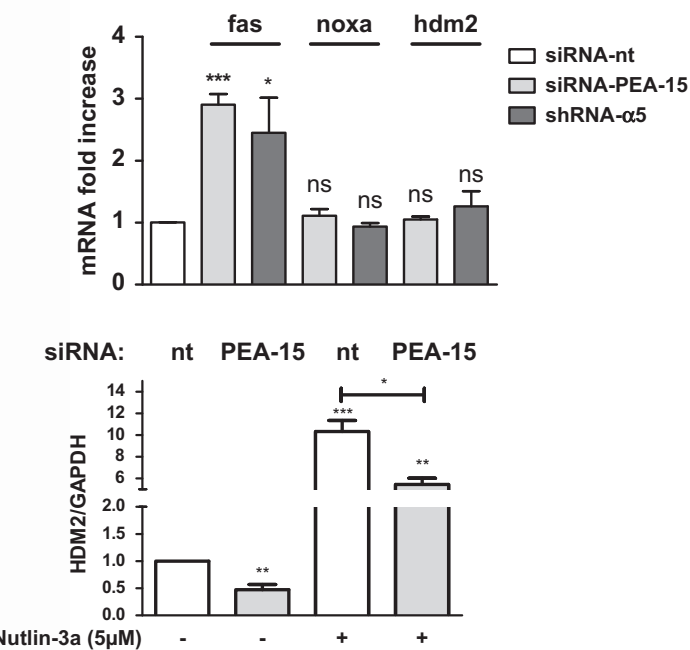

d
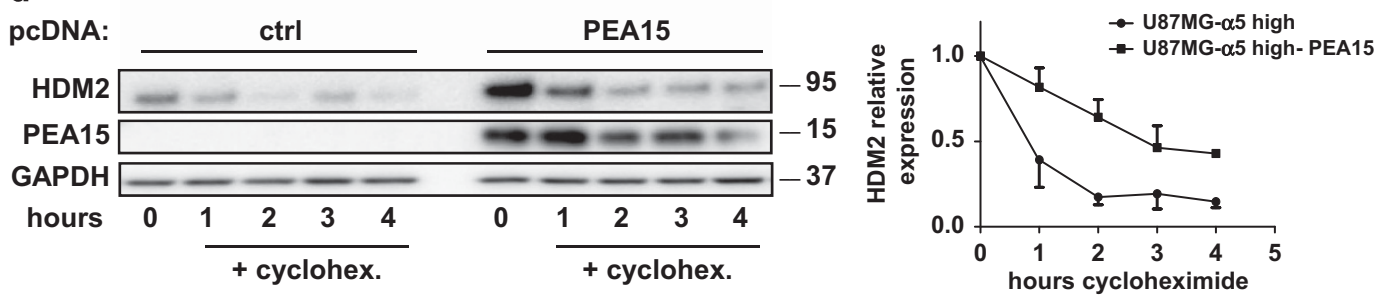

Figure 5 Modulation of the p53 pathway by PEA-15. (a) PEA-15 controls p53 activity. U87MG- $\alpha 5$ high cells were transfected with non-targeting siRNA control (si-nt) or specific for PEA-15 (si-PEA-15) during $24 \mathrm{~h}$ and treated with Nutlin-3a (1 and $5 \mu \mathrm{M})$ or TMZ $(200 \mu \mathrm{M})$ for $12 \mathrm{~h}$. p53 stabilization and activation were analyzed by immunoblots of p53 and pp53ser 15, respectively. GAPDH was used as loading control. Histograms represent mean \pm S.E.M. of three separate experiments with si-nt solvent-treated U87MG- $\alpha 5$ high cells as the reference. (b) p53 transcriptional activity in U87MG- $\alpha 5$ high cells transfected with si-PEA-15 or in U87MG- $\alpha 5$ low cells. RT-qPCR analysis of p53-repressed target gene mRNAs (left: birc5, bcl-2, c-myc) and p53-activated target gene mRNAs (right: fas, noxa, hdm2) is shown. mRNA level of each gene in si-nt-transfected solvent-treated U87MG- $\alpha 5$ high cells served as references. (c) PEA-15 repression decreases HDM2 protein level. U87MG- $\alpha 5$ high cells were transfected with non-targeting siRNA control (si-nt) or specific for PEA-15 (si-PEA) during $24 \mathrm{~h}$ and treated with Nutlin-3a for $12 \mathrm{~h}$. HDM2 protein levels were analyzed by western blot with GAPDH as the loading control. Histograms represent mean \pm S.E.M. of three separate experiments with si-nt solvent-treated U87MG- $\alpha 5$ high cells as the reference. (d) PEA-15 overexpression increases HDM2 protein level and stability. U87MG- $\alpha 5$ high cells were transfected with the pcDNA control vector (ctrl) or with the pcDNA-PEA-15 vector (PEA) during $24 \mathrm{~h}$. Expression of HDM2 was analyzed by western blot in control and PEA-15-overexpressing cells treated with cycloheximide $(1 \mu \mathrm{g} / \mathrm{ml}$ - cyclohex.) over the indicated period. Graph shows the mean \pm S.E.M. of three independent experiments with ${ }^{\star} P<0.05,{ }^{* \star} P<0.01,{ }^{* \star \star} P<0.001 ;$ NS, nonsignificant 


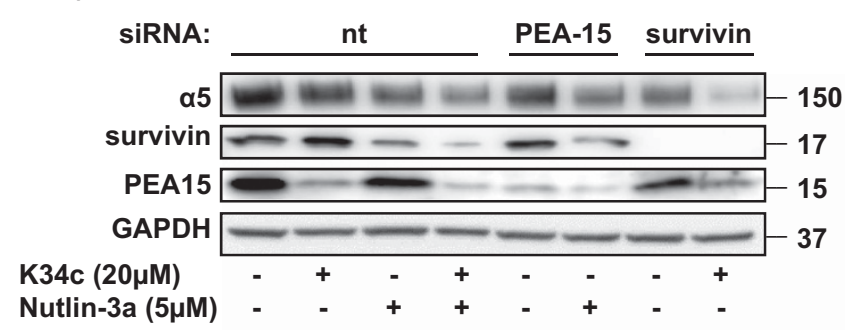

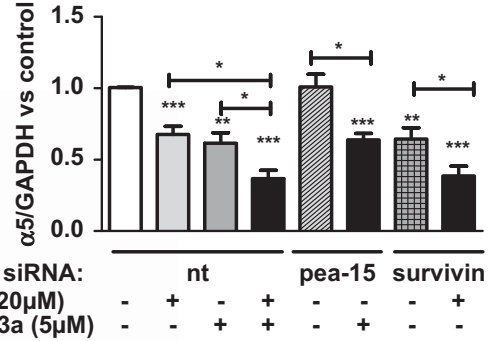

b

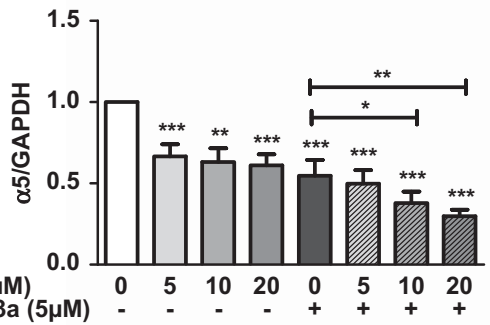

C

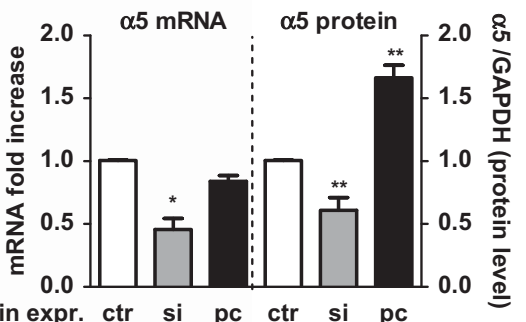

d

pcDNA:

ctrl

survivin
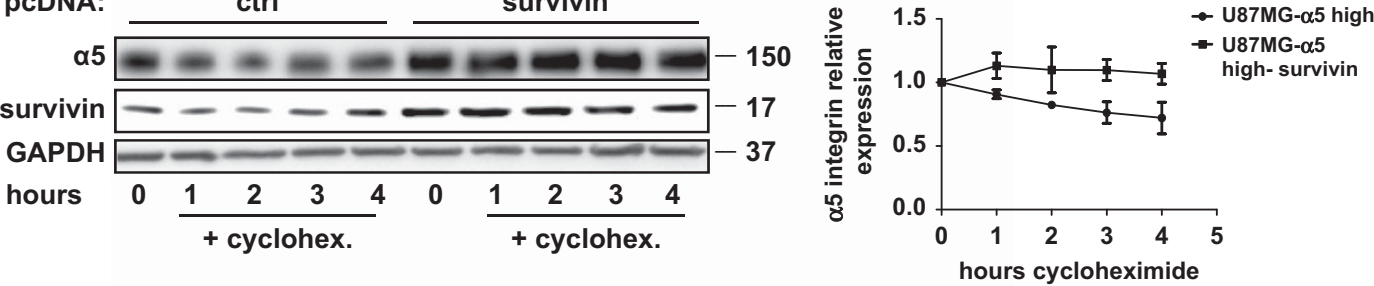

e

LNZ308
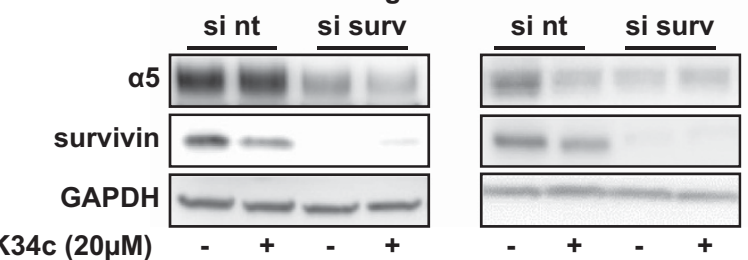

T20
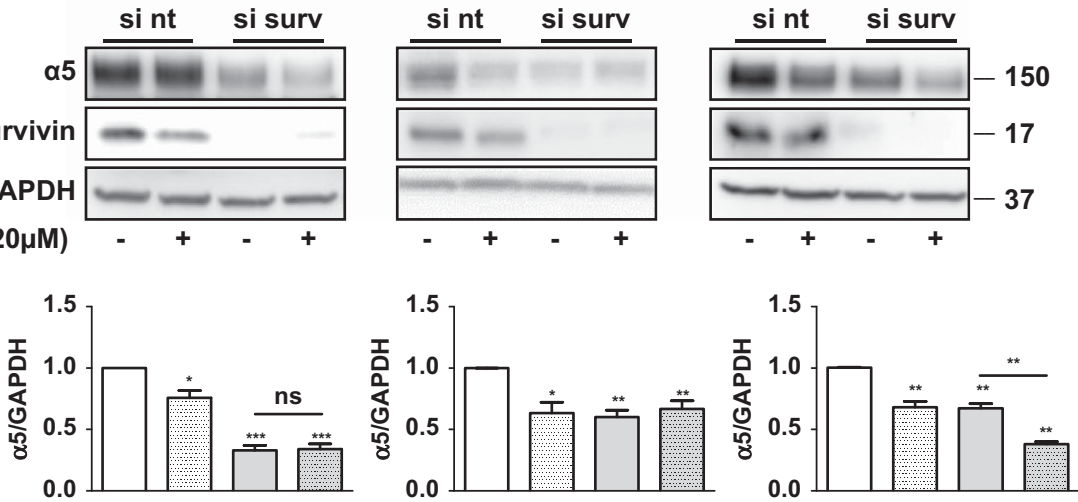

Figure 6 Modulation of $\alpha 5$ integrin expression by survivin and K34c. (a) Survivin controls the $\alpha 5$ integrin expression. U87MG- $\alpha 5$ high cells transfected with si-nt, si-PEA-15 or si-survivin were subjected to $\mathrm{K} 34 \mathrm{c}(20 \mu \mathrm{M})$, Nutlin-3a $(5 \mu \mathrm{M})$ or both treatments for $12 \mathrm{~h}$. Cells were analyzed for $\alpha 5$ integrin, survivin and PEA-15 expression levels by immunoblots. Histograms represent the $\alpha 5$ expression level (normalized with GAPDH as the loading control) in the different experimental conditions compared with si-nt transfected solvent-treated U87MG- $\alpha 5$ high cells. Mean \pm S.E.M. of three separate experiments. (b) U87MG- $\alpha 5$ high cells were treated with increasing concentrations of K34c in the absence or presence of Nutlin-3a $(5 \mu \mathrm{M})$. Expression of $\alpha 5$ integrin was evaluated by western blot. Histograms represent mean \pm S.E.M. of the three independent experiments. (c) Effects of survivin repression (si) or overexpression (pc) on $\alpha 5$ integrin mRNA (left axis) or protein (right axis) level. U87MG- $\alpha 5$ high cells were either transfected with siRNA specific for survivin or with a pcDNA-survivin vector during $24 \mathrm{~h} . \alpha 5 \mathrm{mRNA}$ and protein levels were determined by RT-qPCR or by western blot, respectively and reported to the level in control cells (ctrl - either transfected with non-targeting siRNA or with an empty pcDNA vector). Mean \pm S.E.M. of at least three independent experiments. (d) Survivin overexpression increases $\alpha 5$ integrin expression and stability. U87MG- $\alpha 5$ high cells were transfected with the pcDNA control vector (ctrl) or with the pcDNA-survivin vector (survivin) during $24 \mathrm{~h}$. Expression of $\alpha 5$ integrin was analyzed by western blot in control and survivin overexpressing cells treated with cycloheximide $(1 \mu \mathrm{g} / \mathrm{ml}-\mathrm{cyclohex}$.) over the indicated period. Graph shows the mean \pm S.E.M. of three independent experiments. (e) Survivin controls the $\alpha 5$ integrin expression in different glioma cell lines. U373MG $-\alpha 5$ high cells, LNZ308 cells and the primary GBM cell line T20 were transfected with si-nt or si-survivin and treated with K34c (20 $\mu \mathrm{M})$. Cells were analyzed for $\alpha 5$ integrin and survivin expression levels. Histograms represent the protein expression (normalized with GAPDH as the loading control) in the different cell lines compared with si-nt transfected solvent-treated control cells. Mean \pm S.E.M. of three separate experiments. For all panels: mean \pm S.E.M. with ${ }^{\star} P<0.05,{ }^{* \star} P<0.01,{ }^{* \star} P<0.001$; NS, nonsignificant 
a
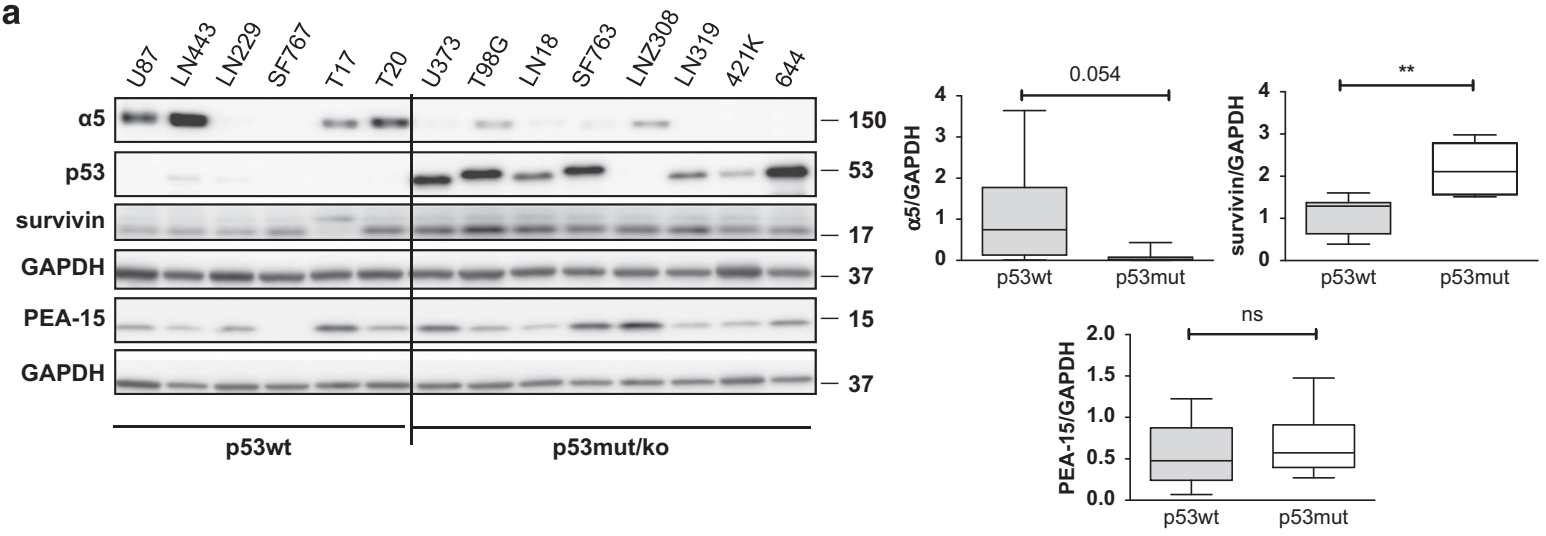

b

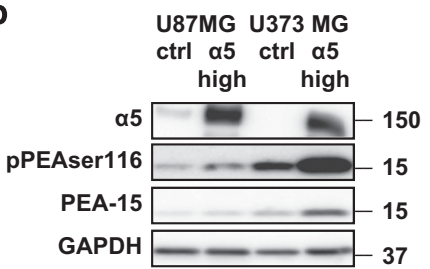

e

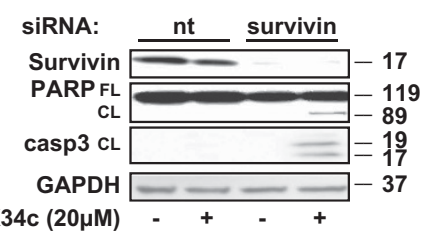

C U373MG- $\alpha 5$ high

p53 mutant

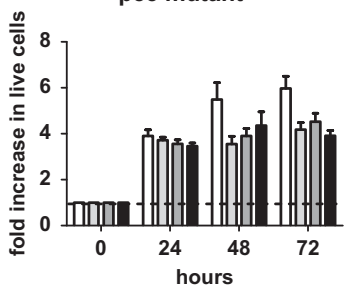

\section{f

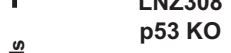

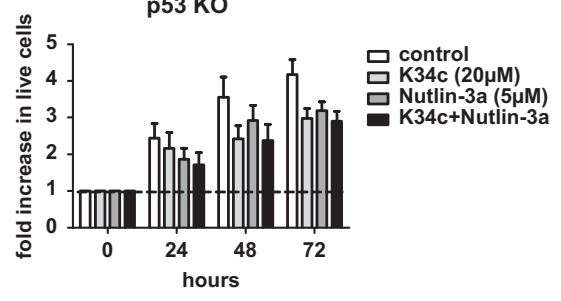

$\square$ control

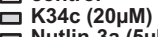

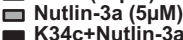

d

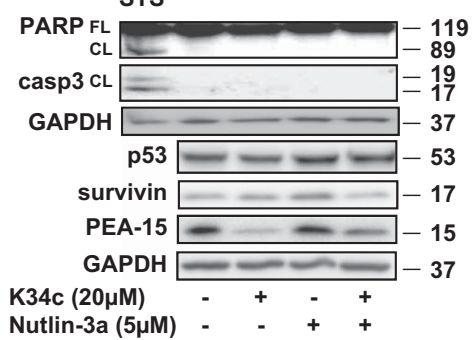

g

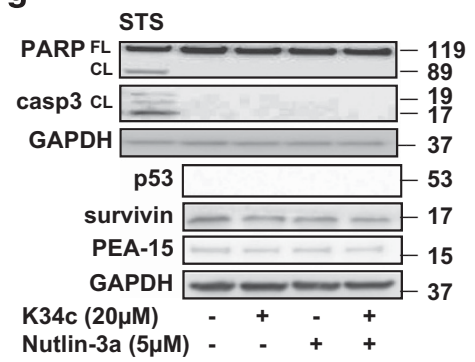

h siRNA: nt surviv PEA surv

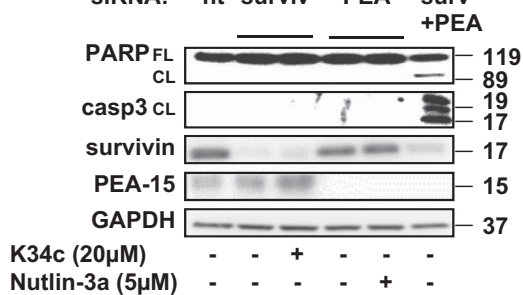

Figure 7 Implication of PEA-15 and survivin in the control of apoptosis in glioma cell lines. (a) Relationships between $\alpha 5$ integrin, survivin, PEA-15 expression levels and p53 status in different glioma cell lines, primary GBM cell lines (T17 and T20) and GBM stem-like cells (NCH421k and NCH644) in basal conditions of culture. Total cell extracts were analyzed by immunoblots. Boxes represent mean \pm S.E.M. of three independent experiments. p53 status of the different cell lines was confirmed by NGS analysis as indicated in Materials and methods section. (b) Relationships between $\alpha 5$ integrin expression and PEA-15. U87MG and U373MG cells either mock-transfected or overexpressing $\alpha 5$ integrin ( $\alpha 5$ high cells) were analyzed by immunoblots for expression of PEA-15 and pPEA-15ser116. (c-e) Role of PEA-15 and survivin in U373MG- $\alpha 5$ high cells. (c) Proliferation of U373MG- $\alpha 5$ high cells treated with K34c $(20 \mu \mathrm{M})$, Nutlin-3a $(5 \mu \mathrm{M})$ or both. Data are reported as fold increase in live cells at 24-, 48- and 72-h treatment as compared with plated live cells at time 0 . Histograms represent the mean \pm S.E.M. of three independent experiments. (d) Effects of the treatments on apoptotic markers (cleaved PARP and Casp 3), survivin and PEA-15 expression levels after $12 \mathrm{~h}$. Staurosporine (STS $-1 \mu \mathrm{M}$ ) was used as a control of functional apoptotic machinery. (e) U373MG- $\alpha 5$ high cells were transfected with siRNA control (si-nt) or specific for survivin (si-survivin) and treated with K34c $(20 \mu \mathrm{M})$. Cells were evaluated for apoptotic markers (cleaved PARP and Casp 3 ) and survivin by immunoblots. (f- $\mathbf{h})$ Role of PEA-15 and survivin in LNZ308 cells. (f) Proliferation of LNZ308 cells treated with K34c (20 $\mu \mathrm{M})$ ), Nutlin-3a (5 $\mu \mathrm{M})$ or both. Data are reported as fold increase in live cells at 24-, 48- and 72-h treatment as compared with plated live cells at time 0 . Histograms represent the mean \pm S.E.M. of three independent experiments. (g) Effects of the treatments on apoptotic markers (cleaved PARP and Casp 3), survivin and PEA-15 expression levels after $12 \mathrm{~h}$. Staurosporine (STS - $1 \mu \mathrm{M}$ ) was used as a control of functional apoptotic machinery. (h) LNZ308 cells were transfected with siRNA control (si-nt), specific for survivin (si-survivin), specific for PEA-15 (si-PEA-15) or both siRNA survivin/siPEA-15. siRNA-survivin cells were treated with $\mathrm{K} 34 \mathrm{c}(20 \mu \mathrm{M})$ and si-PEA-15 cells were treated with Nutlin-3a $(5 \mu \mathrm{M})$. Cell extracts were evaluated for apoptotic markers (cleaved PARP and Casp 3), survivin and PEA-15 expression levels by immunoblots. For all panels: mean \pm S.E.M. with ${ }^{\star \star} P<0.01$; NS, nonsignificant 


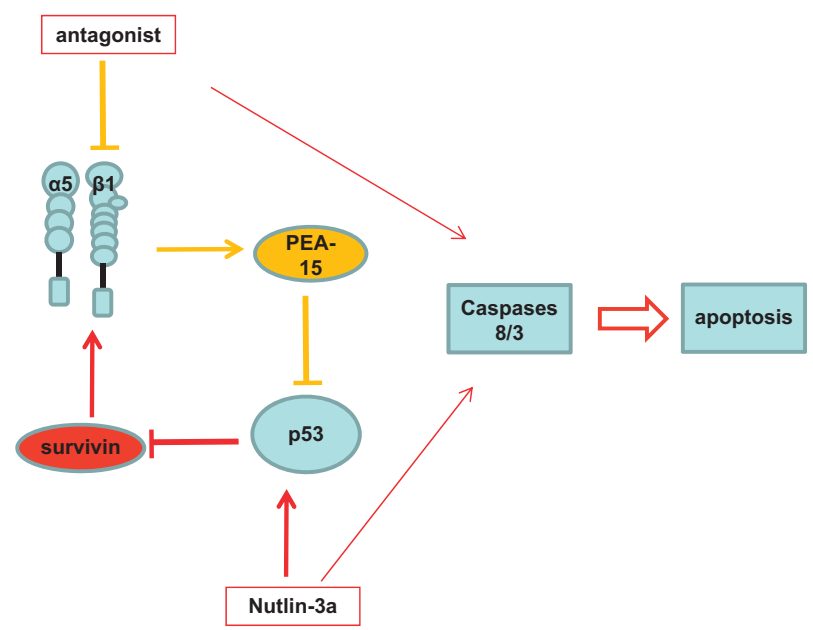

Figure 8 Integrin $\alpha 5 \beta 1$ and $p 53$ interconnected pathways. In normal conditions, glioma cells expressing high level of $\alpha 5$ integrin activate the AKT/PEA-15 pathway leading to an inhibition of p53 transcriptional activity. By inhibition of the integrin pathway, PEA-15 is decreased, HDM2 is destabilized alleviating the repression on p53 and activating the p53-dependent repression of anti-apoptotic genes (in yellow). As a consequence of HDM2 binding to p53, p53 is inactivated/degraded and survivin is expressed at normal level. The inhibition of HDM2/p53 complex by Nutlin-3a increases the p53 stability/activity and p53-dependent repression of survivin, which ultimately impact negatively on $\alpha 5$ integrin expression. This decrease in survivin expression led to a negative control of the $\alpha 5$ integrin, which allows a positive control loop of the cell apoptotic outcome (in red).

\section{Materials and Methods}

Cell lines and compounds. U87MG, U373MG and T98G cells were obtained from ATCC (Molsheim, France) and EACC (Saint Quentin Fallavier, France), respectively. LN443, LN229, LN18, LNZ308 and LN319 cells were kindly provided by Pr M Hegi (Lausanne, Switzerland). SF767 and SF763 were kindly provided by Dr. V Rigot (Marseille, France). All the cell lines were cultured in standard medium as described elsewhere. ${ }^{8}$ Glioma stem cells NCH421k and NCH644 were kindly provided by Dr. C Herold-Mende (Heidelberg, Germany) and maintained in neurosphere culture medium. ${ }^{66}$ Early passage $(<10)$ patient-derived GBM culture T17 and T20 were obtained from human GBM biopsies and used to confirm the data obtained with long-term established cell lines. The p53 status of all cell lines (as indicated in Ishii et al. ${ }^{67}$ ) was confirmed by Next Generation Sequencing on a MiSeq Illumina platform using a TruSeq Custom Amplicon library targeting tumor protein p53 exons 5-11 at a minimum of 500X coverage per sample and by western blot analysis of p53 expression. Accordingly, T17 and T20 primary GBM express a wild-type p53 and NCH421k and NCH644 GBM stem cells expressed both a mutant p53.

U87MG- and U373MG- $\alpha 5$ high and low cells were obtained as described elsewhere. ${ }^{8}$ The U87MG cell line was genetically manipulated to stably overexpress (U87MG- $\alpha 5$ high cells - by transfecting a pcDNA3.1 plasmid containing the human $\alpha 5$ integrin gene, provided by Dr. Ruoshlati, La Jolla, CA, USA) or to stably repress the $\alpha 5$ integrin subunit (U87MG- $\alpha 5$ low cells - by transfecting a pSM2 plasmid coding for a short-hairpin RNA targeting the $\alpha 5$ mRNA, OpenBiosystems, Huntsville, AL, USA). After selection, transfected cells were subcloned to obtain homogenous cell populations. Similarly, U373MG cells stably overexpressing the $\alpha 5$ integrin subunit (U373- $\alpha 5$ high cells) were used in this work. Small non-peptidic integrin antagonists have been described elsewhere ${ }^{27,68}$ (structures, affinities and related publications are given in Supplementary table 1). Briefly, compound 1 and 2/K34c were synthesized on solid support and specifically targets the integrin $\alpha 5 \beta 1$, whereas compound 3 was synthesized in solution and shows selectivity for $\alpha \vee \beta 3$. The biological activities of these small non-peptidic integrin antagonists were determined in a competitive solidphase integrin binding assay.

Integrin $\alpha 5$ and $\alpha v$ blocking antibodies were, respectively, IIA1 (BD Biosciences, Le Pont de Claix, France) and 69.6.5. ${ }^{69}$ MK-2206 was from CliniSciences (Nanterre, France), Z-IETD-fmk and Z-DEVD-fmk from BD Biosciences and Nutlin-3a from Cayman (Interchim, Montluçon, France).
Cell viability and clonogenic assays. Cell viability was determined by Trypan blue exclusion method. Cells were plated (100 000 cells per well) into sixwell plates and treated for 24,48 or $72 \mathrm{~h}$ with solvent or drugs in $2 \%$ FBS containing medium. Viable cells were counted with the TC20 cell counter (Bio-Rad, Marnes La Coquette, France).

Colony formation assay was performed as previously described. ${ }^{8}$ Cells were plated ( 500 cells per well) into six-well culture plates and treated for $72 \mathrm{~h}$ with specific drugs or solvents in $2 \%$ FBS containing medium. Medium was thereafter renewed with fresh $10 \%$ FBS containing medium and cells allowed to grow further for 10 days. Colonies were fixed and stained with crystal violet/ethanol $(0.1 \%$ w/v) and counted. The surviving fraction was determined by the ratio of cells surviving to a specific drug treatment relative to their solvent-treated counterparts.

Western blotting. Proteins were separated on precast gradient 4-20\% SDSPAGE gels (Bio-Rad) and transferred to PVDF membrane (GE Healthcare, Velizy, France). Membranes were probed with primary antibodies against $\alpha 5$ integrin (HI04), FAS, HDM2, BCL2, p21 (Santa Cruz, Heidelberg, Deutschland), p53 (BD Biosciences), GAPDH, PEA15pser116, BAX, c-MYC (Millipore, Molsheim, France). p53pser15, AKT, AKTpser473, GSK3 $\beta$ ser9, cleaved Casp 3, Casp 8, PARP, survivin, PEA-15 and PEA15pser116 antibodies were from Cell Signaling (Ozyme, Saint Quentin Yvelines, France). Immunological complexes were revealed with antirabbit or anti-mouse IgG coupled peroxidase antibodies (Promega, Charbonnieresles-Bains, France) using chemoluminescence (ECL, Bio-Rad) and visualized with Las4000 image analyzer (GE Healthcare). Quantification of non-saturated images was performed with ImageJ software (National institutes of Health, Bethesda, MD, USA). GAPDH was used as the loading control for all samples.

Apoptosis assays. Cells were stained with Annexin V-FITC and PI, and evaluated for apoptosis by flow cytometry (FACS Calibur - Becton-Dickinson, San Jose, CA, USA) as described elsewhere. ${ }^{8}$ Percentage of Annexin V-positive cells (early and late apoptotic cells) was measured using the FlowJo analysis software (Ashland, OR, USA).

Casp 3 activity was determined using a Casp 3 fluorimetric assay kit (SigmaAldrich, Saint Quentin Fallavier, France) according to the manufacturer's instructions. After 12-h cell treatments, cleavage of Ac-DEVD-AMC was assessed at 360/460 nm using a Xenius XM plate reader (Safas, Monaco, UK). As specified in the figure legends, cell permeable inhibitors of Casp 3 or 8 (z-DEVD-fmk or z-IETD-fmk, $50 \mu \mathrm{M}$ ) were incubated $1 \mathrm{~h}$ before the cell treatments.

Cell transfections. Non-targeting siRNA (siGENOME Non-targeting siRNA pool \#2; si-nt) or specific siRNA for human PEA-15 (smart pool ON-TARGET plus PEA-15 siRNA; siPEA-15) and BIRC5 (smart pool ON-TARGET plus birc5 siRNA; sibirc5) were from Dharmacon (Courtaboeuf, France). The transfection reagent jetPRIME was from Polyplus Transfection (Illkirch Graffenstaden, France). Manufacturer's instructions were followed to transiently inhibit the protein expression and transfection efficacy was verified by western blotting of protein of interest.

The pcDNA3.1 vector containing the PEA-15 gene was a kind gift from Dr. Beguinot (Naples, Italy). Cells were transfected with $1 \mu$ g plasmid during $24 \mathrm{~h}$ in Lipofectamine and transfection efficacy was verified by western blot. The pcDNA3.1 vector containing the survivin gene was a kind gift from Dr. Lemarie (Toulouse, France). Cells were transfected with $1 \mu \mathrm{g}$ plasmid during $24 \mathrm{~h}$ and transfection efficacy was verified by western blot.

Real-time PCR analysis. RNA extracted with RNeasy minikit (Qiagen, Courtaboeuf, France), according to the manufacturer protocol, was transcribed into cDNA using the high capacity cDNA kit (Applied Biosystem, Saint Aubin, France). Real-time quantitative PCR was performed using the StepOne Real-Time PCR system (Applied Biosystem) (for primer sequences, see Supplementary Table 2).

Statistical analysis. Data are represented as the mean \pm S.E.M., and $n$ is the number of independent experiments. Statistical analyses were conducted using the Student's $t$-test or the Mann-Whitney test with the GraphPad Prism program (La Jolla, CA, USA). $P<0.05$ was considered significant.

\section{Conflict of Interest}

The authors declare no conflict of interest. 
Acknowledgements. We thank Pr HEGI (Lausanne, Switzerland) for the LN series of glioma cells, Dr. Herold-Mende (Heidelberg, Germany) for the glioma stemlike cells NCH421k and NCH644, and Dr. Rigot (Marseille, France) for the SF763 and SF767 cell lines. We also thank Pr Beguinot (Naples, Italia) for providing the pcDNA3.1-PEA-15 plasmid and Dr. Lemarie (Toulouse, France) for the pcDNAsurvivin plasmid. This work was supported by the University of Strasbourg, the Ligue Contre le Cancer (Comité du Grand Est), the Fondation ARC pour la Recherche sur le Cancer, the Cancéropole Grand Est, the Region Alsace. Guillaume Renner is a predoctoral fellow from the French Ministère de l'Enseignement Supérieur et de la Recherche. H Janouskova was a predoctoral fellow from the French Ministère des Affaires Etrangères and from the Fondation ARC pour la Recherche sur le Cancer.

1. Desgrosellier JS, Cheresh DA. Integrins in cancer: biological implications and therapeutic opportunities. Nat Rev Cancer 2010; 10: 9-22.

2. Goodman SL, Picard M. Integrins as therapeutic targets. Trends Pharmacol Sci 2012; 33: 405-412.

3. Eke I, Cordes N. Focal adhesion signaling and therapy resistance in cancer. Semin Cancer Biol 2014; 31: 65-75.

4. Avraamides CJ, Garmy-Susini B, Varner JA. Integrins in angiogenesis and lymphangiogenesis. Nat Rev Cancer 2008; 8: 604-617.

5. Dingemans AM, van den Boogaart V, Vosse BA, van Suylen RJ, Griffioen AW, Thijssen VL. Integrin expression profiling identifies integrin alpha5 and beta1 as prognostic factors in early stage non-small cell lung cancer. Mol Cancer 2010; 9: 152.

6. Mitra AK, Sawada K, Tiwari P, Mui K, Gwin K, Lengyel E. Ligand-independent activation of c-Met by fibronectin and alpha(5)beta(1)-integrin regulates ovarian cancer invasion and metastasis. Oncogene 2011; 30: 1566-1576.

7. Nam JM, Onodera Y, Bissell MJ, Park CC. Breast cancer cells in three-dimensional culture display an enhanced radioresponse after coordinate targeting of integrin alpha 5 beta 1 and fibronectin. Cancer Res 2010; 70: 5238-5248.

8. Janouskova H, Maglott A, Leger DY, Bossert C, Noulet F, Guerin E et al. Integrin alpha5beta1 plays a critical role in resistance to temozolomide by interfering with the p53 pathway in high-grade glioma. Cancer Res 2012; 72: 3463-3470.

9. Holmes KM, Annala M, Chua CYX, Dunlap SM, Liu YX, Hugen N et al. Insulin-like growth factor-binding protein 2-driven glioma progression is prevented by blocking a clinically significant integrin, integrin-linked kinase, and NF-kappa B network. Proc Natl Acad Sci USA 2012; 109: 3475-3480.

10. Schaffner F, Ray AM, Dontenwill M. Integrin alpha5beta1, the fibronectin receptor, as a pertinent therapeutic target in solid tumors. Cancers 2013; 5: 27-47.

11. Stupp R, Mason WP, van den Bent MJ, Weller M, Fisher B, Taphoorn MJ et al. Radiotherapy plus concomitant and adjuvant temozolomide for glioblastoma. N Engl J Med 2005; 352: 987-996.

12. Hanahan D, Weinberg RA. Hallmarks of cancer: the next generation. Cell 2011; 144: 646-674.

13. Pickup MW, Mouw JK, Weaver VM. The extracellular matrix modulates the hallmarks of cancer. Embo Rep 2014; 15: 1243-1253.

14. Stupp R, Hegi ME, Gorlia T, Erridge SC, Perry J, Hong YK et al. Cilengitide combined with standard treatment for patients with newly diagnosed glioblastoma with methylated MGMT promoter (CENTRIC EORTC 26071-22072 study): a multicentre, randomised, open-label, phase 3 trial. Lancet Oncol 2014; 15: 1100-1108.

15. Vousden KH, Prives C. Blinded by the light: the growing complexity of p53. Cell 2009; 137: 413-431.

16. Ciriello G, Miller ML, Aksoy BA, Senbabaoglu Y, Schultz N, Sander C. Emerging landscape of oncogenic signatures across human cancers. Nat Genet 2013; 45: 1127-U1247.

17. Brennan CW, Verhaak RGW, McKenna A, Campos B, Noushmehr H, Salama SR et al. The somatic genomic landscape of glioblastoma. Cell 2013; 155: 462-477.

18. Verhaak RGW, Hoadley KA, Purdom E, Wang V, Qi Y, Wilkerson MD et al. Integrated genomic analysis identifies clinically relevant subtypes of glioblastoma characterized by abnormalities in PDGFRA, IDH1, EGFR, and NF1. Cancer Cell 2010; 17: 98-110.

19. Viotti J, Duplan E, Caillava C, Condat J, Goiran T, Giordano C et al. Glioma tumor grade correlates with parkin depletion in mutant p53-linked tumors and results from loss of function of p53 transcriptional activity. Oncogene 2014; 33: 1764-1775.

20. Hoe KK, Verma CS, Lane DP. Drugging the p53 pathway: understanding the route to clinical efficacy. Nat Rev Drug Discov 2014; 13: 217-236.

21. Wiman KG. Strategies for therapeutic targeting of the p53 pathway in cancer. Cell Death Differ 2006; 13: 921-926.

22. Ventura A, Kirsch DG, McLaughlin ME, Tuveson DA, Grimm J, Lintault $L$ et al. Restoration of p53 function leads to tumour regression in vivo. Nature 2007; 445: 661-665.

23. Xue W, Zender L, Miething C, Dickins RA, Hernando E, Krizhanovsky V et al. Senescence and tumour clearance is triggered by p53 restoration in murine liver carcinomas. Nature 2007; 445: 656-660.

24. Martinkova E, Maglott A, Leger DY, Bonnet D, Stiborova M, Takeda K et al. Alpha5beta1 integrin antagonists reduce chemotherapy-induced premature senescence and facilitate apoptosis in human glioblastoma cells. Int J Cancer 2010; 127: 1240-1248.
25. Villalonga-Planells R, Coll-Mulet L, Martinez-Soler F, Castano E, Acebes JJ, GimenezBonafe $\mathrm{P}$ et al. Activation of $\mathrm{p} 53$ by Nutlin-3a induces apoptosis and cellular senescence in human glioblastoma multiforme. PLos One 2011; 6: e18588.

26. Janouskova H, Ray AM, Noulet F, Lelong-Rebel I, Choulier L, Schaffner F et al. Activation of p53 pathway by Nutlin-3a inhibits the expression of the therapeutic target alpha5 integrin in colon cancer cells. Cancer Lett 2013; 336: 307-318.

27. Ray AM, Schaffner F, Janouskova H, Noulet F, Rognan D, Lelong-Rebel I et al. Single cell tracking assay reveals an opposite effect of selective small non-peptidic alpha5beta1 or alphavbeta3/beta5 integrin antagonists in U87MG glioma cells. Biochimica et Biophysica acta 2014; 1840: 2978-2987.

28. Hodkinson PS, Elliott T, Wong WS, Rintoul RC, Mackinnon AC, Haslett C et al. ECM overrides DNA damage-induced cell cycle arrest and apoptosis in small-cell lung cancer cells through beta1 integrin-dependent activation of PI3-kinase. Cell Death Differ 2006; 13: 1776-1788.

29. Trencia A, Perfetti A, Cassese A, Vigliotta G, Miele C, Oriente F et al. Protein kinase B/Akt binds and phosphorylates PED/PEA-15, stabilizing its antiapoptotic action. Mol Cell Biol 2003; 23: 4511-4521.

30. Stassi G, Garofalo M, Zerilli M, Ricci-Vitiani L, Zanca C, Todaro M et al. PED mediates AKTdependent chemoresistance in human breast cancer cells. Cancer Res 2005; 65: 6668-6675.

31. Marconi A, Atzei P, Panza C, Fila C, Tiberio R, Truzzi F et al. FLICE/caspase-8 activation triggers anoikis induced by beta1-integrin blockade in human keratinocytes. J Cell Sci 2004; 117: $5815-5823$.

32. Condorelli G, Vigliotta G, Cafieri A, Trencia A, Andalo P, Oriente $F$ et al. PED/PEA-15: an anti-apoptotic molecule that regulates FAS/TNFR1-induced apoptosis. Oncogene 1999; 18: 4409-4415.

33. Shi Y, Nikulenkov F, Zawacka-Pankau J, Li H, Gabdoulline R, Xu J et al. ROS-dependent activation of JNK converts p53 into an efficient inhibitor of oncogenes leading to robust apoptosis. Cell Death Differ 2014; 21: 612-623.

34. Grinkevich VV, Nikulenkov F, Shi Y, Enge M, Bao WJ, Maljukova A et al. Ablation of key oncogenic pathways by RITA-reactivated p53 is required for efficient apoptosis. Cancer Cell 2009; 15: 441-453.

35. McKenzie JA, Liu T, Goodson AG, Grossman D. Survivin enhances motility of melanoma cells by supporting Akt activation and alpha 5 integrin upregulation. Cancer Res 2010; 70: 7927-7937.

36. McKenzie JA, Liu T, Jung JY, Jones BB, Ekiz HA, Welm AL et al. Survivin promotion of melanoma metastasis requires upregulation of alpha(5) integrin. Carcinogenesis 2013; 34: 2137-2144.

37. DeLay M, Jahangiri A, Carbonell WS, Hu YL, Tsao S, Tom MW et al. Microarray analysis verifies two distinct phenotypes of glioblastomas resistant to antiangiogenic therapy. Clin Cancer Res 2012; 18: 2930-2942.

38. Chou FL, Hill JM, Hsieh JC, Pouyssegur J, Brunet A, Glading A et al. PEA-15 binding to ERK $1 / 2$ MAPKs is required for its modulation of integrin activation. J Biol Chem 2003; 278: 52587-52597.

39. Schiller HB, Hermann MR, Polleux J, Vignaud T, Zanivan S, Friedel CC et al. Beta(1)- and alpha(v)-class integrins cooperate to regulate myosin II during rigidity sensing of fibronectinbased microenvironments. Nat Cell Biol 2013; 15: 625-636.

40. Sulzmaier F, Opoku-Ansah J, Ramos JW. Phosphorylation is the switch that turns PEA-15 from tumor suppressor to tumor promoter. Small GTPases 2012; 3: 173-177.

41. Petalidis LP, Oulas A, Backlund M, Wayland MT, Liu L, Plant K et al. Improved grading and survival prediction of human astrocytic brain tumors by artificial neural network analysis of gene expression microarray data. Mol Cancer Ther 2008; 7: 1013-1024.

42. Watanabe $Y$, Yamasaki $F$, Kajiwara $Y$, Saito $T$, Nishimoto $T$, Bartholomeusz $C$ et al. Expression of phosphoprotein enriched in astrocytes $15 \mathrm{kDa}$ (PEA-15) in astrocytic tumors: a novel approach of correlating malignancy grade and prognosis. J Neuro-Oncol 2010; 100: 449-457.

43. Eckert A, Bock BC, Tagscherer KE, Haas TL, Grund K, Sykora J et al. The PEA-15/PED protein protects glioblastoma cells from glucose deprivation-induced apoptosis via the ERK/ MAP kinase pathway. Oncogene 2008; 27: 1155-1166.

44. Hao CH, Beguinot F, Condorelli $C$, Trencia A, Van Meir EG, Yong VW et al. Induction and intracellular regulation of tumor necrosis factor-related apoptosis-inducing ligand (TRAIL) mediated apotosis in human malignant glioma cells. Cancer Res 2001; 61: 1162-1170.

45. Eramo A, Pallini R, Lotti F, Sette G, Patti M, Bartucci M et al. Inhibition of DNA methylation sensitizes glioblastoma for tumor necrosis factor-related apoptosis-inducing ligand-mediated destruction. Cancer Res 2005; 65: 11469-11477.

46. Funke V, Lehmann-Koch J, Bickeboller M, Benner A, Tagscherer KE, Grund K et al. The PEA-15/PED protein regulates cellular survival and invasiveness in colorectal carcinomas. Cancer Lett 2013; 335: 431-440.

47. Condorelli G, Trencia A, Vigliotta G, Perfetti A, Goglia U, Cassese A et al. Multiple members of the mitogen-activated protein kinase family are necessary for PED/PEA-15 anti-apoptotic function. J Biol Chem 2002; 277: 11013-11018.

48. Hendruschk S, Wiedemuth R, Aigner A, Topfer K, Cartellieri M, Martin D et al. RNA interference targeting survivin exerts antitumoral effects in vitro and in established glioma xenografts in vivo. Neuro Oncol 2011; 13: 1074-1089.

49. Kajiwara $Y$, Yamasaki F, Hama S, Yahara K, Yoshioka H, Sugiyama K et al. Expression of survivin in astrocytic tumors - Correlation with malignant grade and prognosis. Cancer 2003; 97: 1077-1083. 
50. Guvenc H, Pavlyukov MS, Joshi K, Kurt H, Banasavadi-Siddegowda YK, Mao P et al. Impairment of glioma stem cell survival and growth by a novel inhibitor for Survivin-Ran protein complex. Clin Cancer Res 2013; 19: 631-642.

51. Lanvin O, Monferran S, Delmas C, Couderc B, Toulas C, Cohen-Jonathan-Moyal E. Radiation-induced mitotic cell death and glioblastoma radioresistance: a new regulating pathway controlled by integrin-linked kinase, hypoxia-inducible factor 1 alpha and survivin in U87 cells. Eur J Cancer 2013; 49: 2884-2891.

52. Dahan P, Martinez Gala J, Delmas C, Monferran S, Malric L, Zentkowski D et al. Ionizing radiations sustain glioblastoma cell dedifferentiation to a stem-like phenotype through survivin: possible involvement in radioresistance. Cell Death Dis 2014; 5: e1543.

53. Kanwar JR, Kamalapuram SK, Kanwar RK. Targeting survivin in cancer: the cell-signalling perspective. Drug Discov Today 2011; 16: 485-494.

54. Cheng SM, Chang YC, Liu CY, Lee JY, Chan HH, Kuo CW et al. YM155 down-regulates survivin and XIAP, modulates autophagy and induces autophagy-dependent DNA damage in breast cancer cells. Br J Pharmacol 2015; 172: 214-234.

55. Mobahat M, Narendran A, Riabowol K. Survivin as a preferential target for cancer therapy. Int J Mol Sci 2014; 15: 2494-2516.

56. Fornaro M, Plescia J, Chheang S, Tallini G, Zhu YM, King M et al. Fibronectin protects prostate cancer cells from tumor necrosis factor-alpha-induced apoptosis via the AKT/ survivin pathway. J Biol Chem 2003; 278: 50402-50411.

57. Vassilev LT, Vu BT, Graves B, Carvajal D, Podlaski F, Filipovic Z et al. In vivo activation of the p53 pathway by small-molecule antagonists of MDM2. Science 2004; 303: 844-848.

58. Li H, Zhang Y, Strose A, Tedesco D, Gurova K, Selivanova G. Integrated high-throughput analysis identifies Sp1 as a crucial determinant of p53-mediated apoptosis. Cell Death Differ 2014; 21: 1493-1502.

59. Issaeva N, Bozko P, Enge M, Protopopova M, LGGC Verhoef, Masucci M et al. Small molecule RITA binds to p53, blocks p53-HDM-2 interaction and activates p53 function in tumors. Nat Med 2004; 10: 1321-1328.
60. de Lange J, Verlaan-de Vries M, Teunisse AF, Jochemsen AG. Chk2 mediates RITA-induced apoptosis. Cell Death Differ 2012; 19: 980-989.

61. Chen YC, Chan JY, Chiu YL, Liu ST, Lozano G, Wang SL et al. Grail as a molecular determinant for the functions of the tumor suppressor p53 in tumorigenesis. Cell Death Differ 2013; 20: 732-743.

62. Zhang HH, Li SZ, Zhang ZY, Hu XM, Hou PN, Gao L et al. Nemo-like kinase is critical for p53 stabilization and function in response to DNA damage. Cell Death Differ 2014; 21: 1656-1663.

63. Liu J, Zhang C, Wang XL, Ly P, Belyi V, Xu-Monette ZY et al. E3 ubiquitin ligase TRIM32 negatively regulates tumor suppressor p53 to promote tumorigenesis. Cell Death Differ 2014; 21: 1792-1804.

64. Jackson JG, Pant V, Li Q, Chang LL, Quintas-Cardama A, Garza D et al. p53-mediated senescence impairs the apoptotic response to chemotherapy and clinical outcome in breast cancer. Cancer Cell 2012; 21: 793-806.

65. Kracikova M, Akiri G, George A, Sachidanandam R, Aaronson SA. A threshold mechanism mediates p53 cell fate decision between growth arrest and apoptosis. Cell Death Differ 2013; 20: 576-588.

66. Campos B, Wan F, Farhadi M, Ernst A, Zeppernick F, Tagscherer KE et al. Differentiation therapy exerts antitumor effects on stem-like glioma cells. Clin Cancer Res 2010; 16: $2715-2728$.

67. Ishii N, Maier D, Merlo A, Tada M, Sawamura Y, Diserens AC et al. Frequent co-alterations of TP53, p16/CDKN2A, p14ARF, PTEN tumor suppressor genes in human glioma cell lines. Brain Pathol 1999; 9: 469-479.

68. Neubauer S, Rechenmacher F, Beer AJ, Curnis F, Pohle K, D'Alessandria C et al. Selective imaging of the angiogenic relevant integrins alpha5beta1 and alphavbeta3. Angewandte Chemie 2013; 52: 11656-11659.

69. Lehmann M, Rabenandrasana C, Tamura R, Lissitzky JC, Quaranta V, Pichon J et al. A monoclonal antibody inhibits adhesion to fibronectin and vitronectin of a colon carcinoma cell line and recognizes the integrins alpha $v$ beta 3 , alpha $v$ beta 5 , and alpha $v$ beta 6 . Cancer Res 1994; 54: 2102-2107.

Supplementary Information accompanies this paper on Cell Death and Differentiation website (http://www.nature.com/cdd) 